\title{
Mass spectrometry-based, label-free quantitative proteomics of round spermatids in mice
}

\author{
HAILONG WANG ${ }^{1}$, YAN LI ${ }^{2}$, LIJUAN YANG ${ }^{1}$, BAOFENG YU $^{1}$, PING YAN $^{1}$, MIN PANG $^{3}$, \\ XIAOBING LI ${ }^{1}$, HONG YANG ${ }^{1}$, GUOPING ZHENG ${ }^{1,4}$, JUN XIE $^{1}$ and RUI GUO ${ }^{1}$ \\ ${ }^{1}$ Department of Biochemistry and Molecular Biology, Shanxi Medical University, Taiyuan, Shanxi 030001; \\ ${ }^{2}$ Fan-Xing Biological Technology Co., Ltd., Beijing 010000; ${ }^{3}$ Respiratory Department, The First Affiliated Hospital, \\ Shanxi Medical University, Taiyuan, Shanxi 030001, P.R. China; ${ }^{4}$ Centre for Transplantation and Renal \\ Research, The University of Sydney at Westmead Millennium Institute, Sydney, NSW 2145, Australia
}

Received March 3, 2014; Accepted March 10, 2014

DOI: $10.3892 / \mathrm{mmr} .2014 .2460$

\begin{abstract}
Round haploid spermatids are formed at the completion of meiosis. These spermatids then undergo morphological and cytological changes during spermiogenesis. Although sperm proteomes have been extensively studied, relatively few studies have specifically investigated the proteome of round spermatids. We developed a label-free quantitative method in combination with 2D-nano-LC-ESI-MS/MS to investigate the proteome of round spermatids in mice. Analysis of the proteomic data identified 2,331 proteins in the round spermatids. Functional classification of the proteins based on Gene Ontology terms and enrichment analysis further revealed the following: 504 of the identified proteins are predicted to be involved in the generation of precursor metabolites and energy; 343 proteins in translation and protein targeting; 298 proteins in nucleotide and nucleic acid metabolism; 275 and 289 proteins in transport and cellular component organization, respectively. A number of the identified proteins were associated with cytoskeleton organization (183), protein degradation (116) and response to stimulus (115). KEGG pathway analysis identified 68 proteins that are annotated as components of the ribosomal pathway and 17 proteins were related to aminoacyl-tRNA biosynthesis. The round spermatids also contained 28 proteins involved in the proteasome pathway and 40 proteins in the lysosome pathway. A total of 60 proteins were annotated as parts of the spliceosome pathway, in which heterogeneous nuclear RNA is converted to mRNA. Approximately 94 proteins were identified as actin-binding proteins, involved in the regulation of the actin cytoskeleton. In conclusion, using a label-free shotgun proteomic approach, we identified numerous proteins associated with spermiogenesis in round spermatids.
\end{abstract}

Correspondence to: Professor Rui Guo, Department of Biochemistry and Molecular Biology, Shanxi Medical University, No. 56 Xinjian South Road, Taiyuan, Shanxi 030001, P.R. China E-mail: ruiguocn@163.com

Key words: proteome, round spermatid, label-free quantification, spermatogenesis

\section{Introduction}

Mammalian spermatogenesis is a complex and highly ordered process, in which a diploid progenitor germ cell transforms to highly specialised spermatozoa. This process involves successive mitotic, meiotic and post-meiotic phases. Once meiosis is completed, haploid germ cells termed 'round spermatids' are produced; these spermatids subsequently undergo a series of differentiation steps collectively known as 'spermiogenesis'. In spermiogenesis, round spermatids develop a distinct head, midpiece and tail region; round spermatids also undergo chromatin remodelling, develop an acrosome and become almost completely devoid of cytoplasm. These changes lead to the formation of slender, elongated, mature spermatids, which are released into the lumen of the seminiferous tubule during spermiation (1).

Round haploid spermatids initiate spermiogenesis; successful spermiogenesis is necessary for fertilization, and alterations of this process constitute an important cause of male infertility. This process requires a precise and well coordinated system that regulates the constantly changing patterns of gene and protein expression (2). Therefore, the identification of proteins present in the spermatids can not only provide insights into the molecular basis of spemiogenesis, but also facilitate the identification of cell-specific targets for the diagnosis or induction of male infertility.

Numerous genes involved in spermatogenesis have been identified by differential display (3), serial analysis of gene expression (SAGE) (4) and microarray methods (5). Nevertheless, these methods do not provide pivotal information on the post-transcriptional control of gene expression, changes in protein expression levels and/or protein modifications. In this context, proteomics research has emerged and enhanced our knowledge on cell behavior at the system level, by revealing global patterns of protein content, modification and activity during development (6). Experiments have also been conducted to initiate differential protein expression profiling studies and/or systematic analyses of testicular proteomes in entire organs or isolated spermatogenic cells from various species. Several groups have focused on sperm proteomes, and identified numerous proteins that characterise sperm cells in 
different mammals (7-11). Although proteomic analyses of the sperm and of different developmental stages of the testis have been performed in different mammalian species, the protein expression profiles of spermiogenesis, particularly of round spermatids, remain unclear.

Mass spectrometry (MS)-based proteomics technology is a powerful tool for large-scale protein identification and quantification (12). Previous proteomic studies have used techniques such as two-dimensional (2-D) polyacrylamide gel electrophoresis (PAGE) and 1-D PAGE of the extracted protein mixture prior to liquid chromatography (LC)-MS/MS identification. Although these techniques require the reduction of sample complexity prior to LC-MS/MS analysis, proteins present in small amounts may not be detectable on the gel, thereby limiting the capacity of MS to identify a number of protein components. A number of quantitative proteomic methods have been developed, including stable isotope labeling and label-free methods (11). The latter is applicable in complex biological systems; in addition, this technique has a number of advantages, such as faster, cleaner and simpler results $(13,14)$. Numerous researchers have employed label-free shotgun proteomic techniques (15-17).

Animal models are commonly used to study the molecular regulation of spermatogenesis. Numerous murine models have been established and applied to study the genes that are up- or downregulated in spermatogenesis. Biologically, meiosis and spermiogenesis are quite similar processes between humans and rodents. In the current study, label-free quantitative shotgun proteomics and mass spectrometry were combined to investigate the protein content of the round spermatids of mice, in order to provide new insights into the molecular regulation of spermiogenesis.

\section{Materials and methods}

Sample preparation. Round spermatids were isolated according to a previously described method (18) with slight modifications. In the first wave of mouse spermatogenesis, different spermatogenic cells were found at specific time points (days $6,9,14,21,35$ and 60 postpartum). Based on the majority of germ cell types, male mice of different ages are commonly used to isolate differently developed stages of spermatogenic cell types. In this study, ten 35-day old male Balb/c mice were used to isolate round spermatids. The mice were anesthetized with $\mathrm{CO}_{2}$ and sacrificed by cervical dislocation. The testes were then removed and decapsulated. The tubulous tissue was cut into small pieces and incubated in $5 \mathrm{ml}$ of phosphate-buffered saline (PBS) containing $0.5 \mathrm{mg} / \mathrm{ml}$ of collagenase (Sigma-Aldrich, St. Louis, MO, USA) with continuous agitation at $33^{\circ} \mathrm{C}$ for $15 \mathrm{~min}$. The dispersed seminiferous cords and cells were allowed to sediment for $5 \mathrm{~min}$ and the supernatant was decanted. The pellet was resuspended in $5 \mathrm{ml}$ of PBS containing $0.5 \mathrm{mg} / \mathrm{ml}$ of trypsin (Sigma-Aldrich) and $1 \mu \mathrm{g} / \mathrm{ml}$ of DNase (Promega, Madison, WI, USA), and incubated under the same conditions for $15 \mathrm{~min}$. The tissue was dissociated to disperse seminiferous cells by gently pipetting with a Pasteur pipette; the cell suspension was then centrifuged at $80 \mathrm{x}$ g for $10 \mathrm{~min}$. The pellet was washed twice with PBS, filtered using a filter cloth (200 mesh) and resuspended in $20 \mathrm{ml}$ of PBS solution containing $0.5 \%$ bovine serum albumin (BSA).
A total of $10^{8}$ cells were bottom-loaded in a cell separator apparatus with a $12.5 \mathrm{~cm}$ diameter (TH-300A; Shanghai Huxi Analysis Instrument Factory Co., Ltd., Shanghai, China) and then incubated in a 2-4\% BSA linear gradient in RPMI-1640 medium (Gibco, Grand Island, NY, USA). After 3 h of velocity sedimentation at unit gravity, the cell fractions (10 $\mathrm{ml} /$ fraction) were collected from the bottom of the separator apparatus at a rate of $5 \mathrm{ml} / \mathrm{min}$. The cell types, in terms of diameter and morphological characteristics, as well as the purity of each fraction, were assessed under a light microscope (BX43; Olympus Co., Tokyo, Japan). Only fractions with the expected cell type were pooled together. The average purity of round spermatids was $95 \%$.

Protein extraction. Cells were washed twice with PBS and then lysed by sonication on ice in a buffer containing $7 \mathrm{M}$ urea, $2 \mathrm{M}$ thiourea, 4\% CHAPS, 65 mM DTT and 0.2\% Biolyte (Bio-Rad, Richmond, CA, USA). Following sonication, the lysates were centrifuged $\left(10,000 \times \mathrm{g}, 1 \mathrm{~h}\right.$ at $\left.4^{\circ} \mathrm{C}\right)$, and the supernatants were collected. The protein concentration of each supernatant was assayed using a standard Bradford protein assay kit (Bio-Rad). Approximately $100 \mu \mathrm{g}$ of the protein sample was reduced using $10 \mathrm{mM}$ DTT at $37^{\circ} \mathrm{C}$ for $2.5 \mathrm{~h}$, and alkylated with $50 \mathrm{mM}$ iodoacetamide (both from Sigma-Aldrich) at room temperature for $40 \mathrm{~min}$. The sample was then diluted in a solution of $50 \mathrm{mM}$ $\mathrm{NH}_{4} \mathrm{HCO}_{3}$ (Sigma-Aldrich). The protein mixture was digested by incubating in grade-modified trypsin (Promega) at a 1:50 enzyme:protein ratio, at $37^{\circ} \mathrm{C}$ for $20 \mathrm{~h}$. The tryptic peptide mixture was lyophilized and stored at $-80^{\circ} \mathrm{C}$ until use.

Immunofluorescent detection. Cells were attached to poly-L-lysine coated microscopy coverslips and were fixed with $2 \%$ formaldehyde in microtubule-stabilizing buffer (50 mmol/1 PIPES, $5 \mathrm{mmol} / \mathrm{l}$ EGTA and $5 \mathrm{mmol} / 1 \mathrm{MgSO}_{4}$ ) for $1 \mathrm{~h}$. Coverslips were rinsed in PBS and permeabilized for $1 \mathrm{~h}$ in $1 \%$ Triton X-100 in PBS. Nonspecific antibody binding was prevented by incubation for $1 \mathrm{~h}$ in $10 \%$ normal goat serum. Microtubules were labeled with anti- $\alpha$-tubulin monoclonal (Sigma-Aldrich). Primary antibodies were detected using FITC-conjugated rabbit anti-mouse immunoglobulin (Jackson ImmunoResearch Inc., West Grove, PA, USA). DNA was detected by labeling with DAPI. The coverslips were mounted in a drop of VectaShield mounting medium (Vector Laboratories Inc, Burlingame, CA, USA). Coverslips were examined using BX43 Epifluorescence microscope (Olympus Co.).

Automated 2D-nano-LC-ESI-MS/MS peptide analysis. The extracted peptides were desalted using $1.3 \mathrm{ml} \mathrm{C18}$ solid-phase extraction column (Sep-Pak ${ }^{\circledR}$ Cartridge; Waters Corp., Milford, MA, USA). The peptides were dried using a vacuum centrifuge and were resuspended in loading buffer containing $5 \mathrm{mM}$ ammonium formate $\left(\mathrm{NH}_{4} \mathrm{FA}\right)$ and $5 \%$ acetonitrile at $\mathrm{pH}$ 3.0, Next, peptides were separated and analyzed by 2D strong cation-exchange (SCX)/reversed-phase (RP) nano-scale LC/MS. The experiments were performed on a Nano Aquity UPLC system (Waters Corp.) connected to an LTQ Orbitrap XL mass spectrometer (Thermo Electron Corp., Bremen, Germany) equipped with an online nano-electrospray ion source (Bruker, Auburn, CA, USA). 


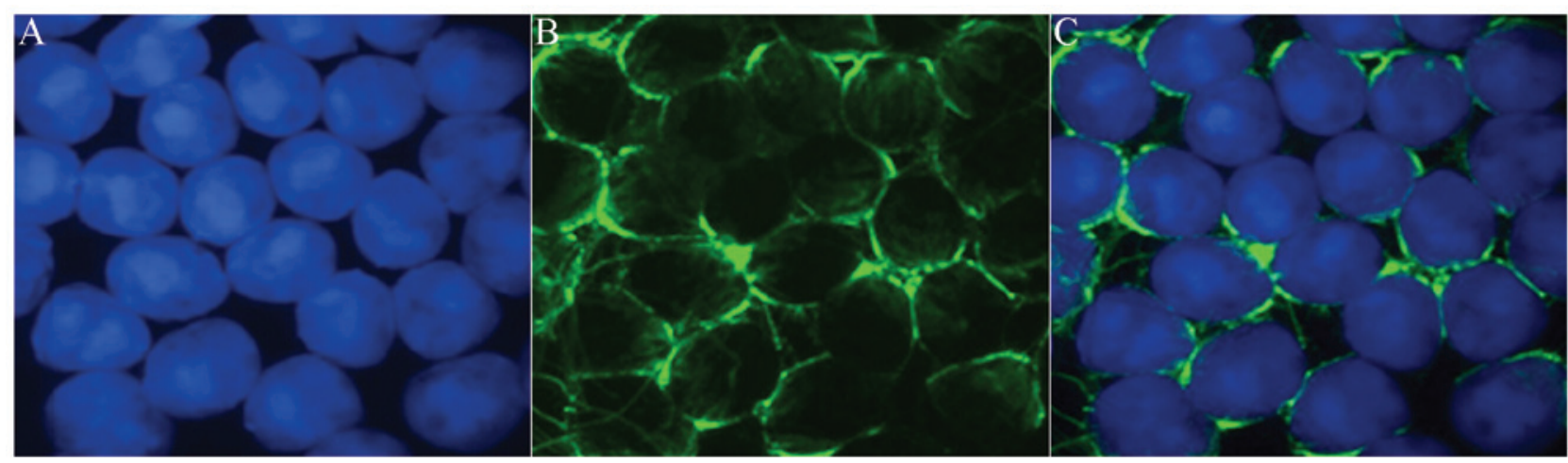

Figure 1. Immunofluorescent staining of purified mouse round spermatids with (A) DAPI (blue), (B) anti- $\alpha$-tubulin (green), and (C) DAPI and anti- $\alpha$-tubulin. Strong anti- $\alpha$-tubulin staining was observed in almost all cells. Scale bar, $20 \mu \mathrm{m}$.

A $180 \mu \mathrm{m} \times 2.4 \mathrm{~cm} \mathrm{SCX} \mathrm{column} \mathrm{(Waters} \mathrm{Corp),} \mathrm{which}$ was packed with $5 \mu \mathrm{m}$ of polysulfoethyl aspartamide (PolyLC Inc., Columbia, MD, USA) was used for the first dimension. To recover hydrophobic peptides retained on the SCX column after a conventional salt step gradient, an RP step gradient from 5 to $50 \%$ acetonitrile (ACN) was applied to the SCX column. A $15-\mu l$ plug was performed at each step of the gradient. The SCX column was cleaned once using $1 \mathrm{M} \mathrm{NH}_{4} \mathrm{FA}$. The plugs were then loaded onto the SCX column with loading buffer, at a flow rate of $15 \mu \mathrm{l} / \mathrm{min}$ for $6 \mathrm{~min}$. A peptide sample $(15 \mu \mathrm{l})$ was loaded onto the SCX column prior to injection of the gradient plugs. The eluted peptides were then captured using a trap column (Waters Corp.), and salts were diverted to waste. The trap column $(2 \mathrm{~cm} \mathrm{x} 180 \mu \mathrm{m})$ was packed with a $5 \mu \mathrm{m}$ Symmetry ${ }^{\circledR} \mathrm{C} 18$ column (Waters Corp.). The RP analytical column $(15 \mathrm{~cm} \times 100 \mu \mathrm{m})$ was packed with a $1.7 \mu \mathrm{m}$ bridged ethyl hybrid (BEH) C18 particle (Waters Corp.) and then used for protein separation at the second dimension.

The peptides on the RP analytical column were eluted with a three-step linear gradient, balancing with the $95 \%$ A buffer $10 \mathrm{~min}$, then starting from 5 to $40 \% \mathrm{~B}$ in $40 \mathrm{~min}$ (A, water with $0.1 \%$ formic acid; $\mathrm{B}, \mathrm{ACN}$ with $0.1 \%$ formic acid) and increased up to $80 \%$ B in 3 min. Afterwards, this solution was reduced to $5 \% \mathrm{~B}$ for $2 \mathrm{~min}$. The column was left to re-equilibrate for $15 \mathrm{~min}$. The column flow rate was maintained at $500 \mathrm{nl} / \mathrm{min}$ and the column temperature was maintained at $35^{\circ} \mathrm{C}$. Eluted peptides were ionized at $1.9 \mathrm{kV}$ and the ions were analyzed by an LTQ Orbitrap XL Mass spectrometer (Thermo Fisher Scientific Inc., Marietta, OH, USA).

The LTQ Orbitrap XL mass spectrometer was operated in a data-dependent mode to switch automatically between MS and MS/MS acquisition. Survey full-scan MS spectra with two microscans $(300-1800 \mathrm{~m} / \mathrm{z})$ were acquired in the Obitrap with a mass resolution of 60,000 at $400 \mathrm{~m} / \mathrm{z}$. Ten sequential LTQ-MS/MS scans were then conducted. Dynamic exclusion was used with two repeat counts, $10 \mathrm{sec}$ repeat duration and $90 \mathrm{sec}$ exclusion duration. For MS/MS, precursor ions were activated using a $35 \%$ normalized collision energy at the default activation q-value of 0.25 .

Peptide sequencing data analysis. The acquired MS/MS spectra were searched against the IPI mouse.v3.68 fasta-formatted protein database using the SEQUEST v.28 (revision 12) software (Thermo Electron Corp.). To reduce identification of false positives, we appended to the database its decoy version containing the reverse sequences. The search parameters were the following: partial trypsin (KR) cleavage with two missed cleavages; the variable modification was oxidation (M); peptide mass tolerance, $50 \mathrm{ppm}$; and fragment ion tolerance, $1 \mathrm{Da}$. The open-source Trans Proteomic Pipeline software (revision 4.0; Institute of Systems Biology, Seattle, WA, USA) was then used to identify proteins based on the corresponding peptide sequences and $\mathrm{a} \geq 95 \%$ confidence threshold. The peptides results were filtered by Peptide Prophet (19) with a p-value $>0.95$ and a Protein Prophet (20) probability of 0.95 was used for the protein identification results.

Bioinformatic analyses. The predicted cellular localization of the proteins identified in the round spermatids was retrieved based on the information available at the Gene Ontology (GO) project website (http://www.geneontology.org/). Functional classification of the proteins was based on biological process and molecular function GO terms. Assignment of the proteins to signaling pathways was based on information available at the Kyoto Encyclopedia of Genes and Genomes (KEGG) (http://www.genome.jp/kegg/pathway.html) and the BioCarta (http://www.biocarta.com/genes/index.asp) databases. Enrichment analysis for these categorizations was performed with tools available at DAVID Bioinformatics Resources (http://david.abcc.ncifcrf.gov/); DAVID is a web-based application that enables visualization, discovery and analysis of molecular interactions and associations with disease for a given list of genes or proteins.

\section{Results}

Identification of proteins in round spermatids by shotgun proteomics. Following isolation of murine testicular cells by a gradient method, the purity of the sorted round spermatids was assessed by immunofluorescent staining using the anti- $\alpha$-tubulin antibody. $\alpha$-tubulin is the main component of manchette, which is a spermatid-specific microtubular structure. The purity of the sorted round spermatids was $>95 \%$, as assessed by counting 500 sorted cells under the microscope (Fig. 1).

We employed a label-free shotgun proteomic technique to identify proteins, gain insights into the protein expression profile of round spermatids, and investigate the relevant molecular mechanisms. The reproducibility of the method was evaluated, with a reliability coefficient of $95 \%$ estimated from independent 
Table I. Enriched biological processes in the proteome of round spermatids based on Gene Ontology (GO) terms.

\begin{tabular}{|c|c|c|c|c|}
\hline GO id. & Description & Count & $\%$ & $\mathrm{Q}<0.01$ \\
\hline GO:0055114 & Oxidation reduction & 234 & 10.3356890460 & $4.40 \mathrm{E}-58$ \\
\hline GO:0008104 & Protein localization & 198 & 8.7455830389 & $1.24 \mathrm{E}-50$ \\
\hline GO:0045184 & Establishment of protein localization & 180 & 7.9505300353 & 4.11E-33 \\
\hline GO:0015031 & Protein transport & 179 & 7.9063604240 & $9.98 \mathrm{E}-31$ \\
\hline GO:0006091 & $\begin{array}{l}\text { Generation of precursor metabolites } \\
\text { and energy }\end{array}$ & 142 & 6.2720848057 & $2.54 \mathrm{E}-24$ \\
\hline GO:0046907 & Intracellular transport & 135 & 5.9628975265 & $2.68 \mathrm{E}-24$ \\
\hline GO:0006412 & Translation & 126 & 5.5653710247 & $2.77 \mathrm{E}-24$ \\
\hline GO:0042592 & Homeostatic process & 114 & 5.0353356890 & $5.88 \mathrm{E}-24$ \\
\hline GO:0016192 & Vesicle-mediated transport & 105 & 4.6378091873 & $1.32 \mathrm{E}-23$ \\
\hline GO:0007155 & Cell adhesion & 100 & 4.4169611307 & $1.30 \mathrm{E}-21$ \\
\hline GO:0022610 & Biological adhesion & 100 & 4.4169611307 & $2.13 \mathrm{E}-21$ \\
\hline GO:0034613 & Cellular protein localization & 97 & 4.2844522968 & $7.58 \mathrm{E}-20$ \\
\hline GO:0070727 & Cellular macromolecule localization & 97 & 4.2844522968 & $5.06 \mathrm{E}-19$ \\
\hline GO:0006886 & Intracellular protein transport & 93 & 4.1077738516 & $1.53 \mathrm{E}-18$ \\
\hline GO:0006396 & RNA processing & 90 & 3.9752650177 & $2.20 \mathrm{E}-18$ \\
\hline GO:0044271 & Nitrogen compound biosynthetic process & 88 & 3.8869257951 & $2.54 \mathrm{E}-18$ \\
\hline GO:0016071 & mRNA metabolic process & 84 & 3.7102473498 & $5.99 \mathrm{E}-18$ \\
\hline GO:0055085 & Transmembrane transport & 83 & 3.6660777385 & $1.56 \mathrm{E}-17$ \\
\hline GO:0019725 & Cellular homeostasis & 81 & 3.5777385159 & $5.15 \mathrm{E}-17$ \\
\hline GO:0043933 & Macromolecular complex subunit organization & 78 & 3.4452296820 & $5.78 \mathrm{E}-17$ \\
\hline GO:0006397 & mRNA processing & 77 & 3.4010600707 & $7.10 \mathrm{E}-16$ \\
\hline GO:0065003 & Macromolecular complex assembly & 76 & 3.3568904594 & $1.18 \mathrm{E}-15$ \\
\hline GO:0051186 & Cofactor metabolic process & 73 & 3.2243816254 & $1.27 \mathrm{E}-15$ \\
\hline GO:0007010 & Cytoskeleton organization & 71 & 3.1360424028 & $5.24 \mathrm{E}-15$ \\
\hline GO:0022900 & Electron transport chain & 67 & 2.9593639576 & $8.39 \mathrm{E}-15$ \\
\hline GO:0008380 & RNA splicing & 67 & 2.9593639576 & $1.13 \mathrm{E}-14$ \\
\hline GO:0005996 & Monosaccharide metabolic process & 64 & 2.8268551237 & $1.89 \mathrm{E}-14$ \\
\hline GO:0006732 & Coenzyme metabolic process & 60 & 2.6501766784 & $1.89 \mathrm{E}-14$ \\
\hline GO:0019318 & Hexose metabolic process & 60 & 2.6501766784 & $1.97 \mathrm{E}-14$ \\
\hline GO:0006163 & Purine nucleotide metabolic process & 59 & 2.6060070671 & $1.97 \mathrm{E}-14$ \\
\hline GO:0034654 & $\begin{array}{l}\text { Nucleobase, nucleoside, nucleotide and } \\
\text { nucleic acid biosynthetic process }\end{array}$ & 59 & 2.6060070671 & $2.69 \mathrm{E}-14$ \\
\hline GO:0034404 & $\begin{array}{l}\text { Nucleobase, nucleoside and nucleotide } \\
\text { biosynthetic process }\end{array}$ & 59 & 2.6060070671 & $3.59 \mathrm{E}-14$ \\
\hline GO:0034621 & $\begin{array}{l}\text { Cellular macromolecular complex } \\
\text { subunit organization }\end{array}$ & 59 & 2.6060070671 & $5.07 \mathrm{E}-14$ \\
\hline GO:0009165 & Nucleotide biosynthetic process & 58 & 2.5618374558 & $5.92 \mathrm{E}-14$ \\
\hline GO:0016044 & Membrane organization & 58 & 2.5618374558 & $9.05 \mathrm{E}-14$ \\
\hline GO:0048878 & Chemical homeostasis & 58 & 2.5618374558 & $1.13 \mathrm{E}-13$ \\
\hline GO:0006631 & Fatty acid metabolic process & 57 & 2.5176678445 & $1.46 \mathrm{E}-13$ \\
\hline GO:0034622 & Cellular macromolecular complex assembly & 57 & 2.5176678445 & $1.48 \mathrm{E}-13$ \\
\hline GO:0009259 & Ribonucleotide metabolic process & 56 & 2.4734982332 & $1.53 \mathrm{E}-13$ \\
\hline GO:0009611 & Response to wounding & 56 & 2.4734982332 & $1.89 \mathrm{E}-13$ \\
\hline GO:0009150 & Purine ribonucleotide metabolic process & 55 & 2.4293286219 & $4.22 \mathrm{E}-13$ \\
\hline GO:0032989 & Cellular component morphogenesis & 55 & 2.4293286219 & $4.40 \mathrm{E}-13$ \\
\hline GO:0006006 & Glucose metabolic process & 54 & 2.3851590106 & $5.52 \mathrm{E}-13$ \\
\hline GO:0030030 & Cell projection organization & 54 & 2.3851590106 & $6.21 \mathrm{E}-13$ \\
\hline GO:0015980 & $\begin{array}{l}\text { Energy derivation by oxidation of } \\
\text { organic compounds }\end{array}$ & 53 & 2.3409893993 & $7.03 \mathrm{E}-13$ \\
\hline GO:0006164 & Purine nucleotide biosynthetic process & 53 & 2.3409893993 & $1.41 \mathrm{E}-12$ \\
\hline GO:0007264 & Small GTPase mediated signal transduction & 53 & 2.3409893993 & $1.62 \mathrm{E}-12$ \\
\hline
\end{tabular}


Table I. Continued.

\begin{tabular}{|c|c|c|c|c|}
\hline GO id. & Description & Count & $\%$ & $\mathrm{Q}<0.01$ \\
\hline GO:0030029 & Actin filament-based process & 52 & 2.2968197880 & $1.65 \mathrm{E}-12$ \\
\hline GO:0009260 & Ribonucleotide biosynthetic process & 51 & 2.2526501767 & $2.84 \mathrm{E}-12$ \\
\hline GO:0006457 & Protein folding & 51 & 2.2526501767 & $4.68 \mathrm{E}-12$ \\
\hline GO:0008610 & Lipid biosynthetic process & 51 & 2.2526501767 & $5.69 \mathrm{E}-12$ \\
\hline GO:0050801 & Ion homeostasis & 51 & 2.2526501767 & $5.93 \mathrm{E}-12$ \\
\hline GO:0009152 & Purine ribonucleotide biosynthetic process & 50 & 2.2084805654 & $6.56 \mathrm{E}-12$ \\
\hline GO:0030036 & Actin cytoskeleton organization & 50 & 2.2084805654 & $7.59 \mathrm{E}-12$ \\
\hline GO:0009141 & Nucleoside triphosphate metabolic process & 49 & 2.1643109541 & 8.27E-12 \\
\hline GO:0009144 & Purine nucleoside triphosphate metabolic process & 48 & 2.1201413428 & 8.27E-12 \\
\hline GO:0009205 & Purine ribonucleoside triphosphate metabolic process & 47 & 2.0759717314 & $9.26 \mathrm{E}-12$ \\
\hline GO:0009199 & Ribonucleoside triphosphate metabolic process & 47 & 2.0759717314 & $1.50 \mathrm{E}-11$ \\
\hline GO:0006461 & Protein complex assembly & 47 & 2.0759717314 & $1.50 \mathrm{E}-11$ \\
\hline GO:0070271 & Protein complex biogenesis & 47 & 2.0759717314 & $1.50 \mathrm{E}-11$ \\
\hline GO:0006873 & Cellular ion homeostasis & 47 & 2.0759717314 & $2.68 \mathrm{E}-11$ \\
\hline GO:0055082 & Cellular chemical homeostasis & 47 & 2.0759717314 & 4.71E-11 \\
\hline GO:0032268 & Regulation of cellular protein metabolic process & 46 & 2.0318021201 & $2.46 \mathrm{E}-10$ \\
\hline GO:0008283 & Cell proliferation & 45 & 1.9876325088 & $2.89 \mathrm{E}-10$ \\
\hline GO:0009145 & Purine nucleoside triphosphate biosynthetic process & 44 & 1.9434628975 & 4.24E-10 \\
\hline GO:0009142 & Nucleoside triphosphate biosynthetic process & 44 & 1.9434628975 & $9.73 \mathrm{E}-10$ \\
\hline GO:0009206 & Purine ribonucleoside triphosphate biosynthetic process & 43 & 1.8992932862 & $1.48 \mathrm{E}-09$ \\
\hline GO:0009201 & Ribonucleoside triphosphate biosynthetic process & 43 & 1.8992932862 & $1.48 \mathrm{E}-09$ \\
\hline GO:0045333 & Cellular respiration & 42 & 1.8551236749 & $1.53 \mathrm{E}-09$ \\
\hline GO:0046034 & ATP metabolic process & 42 & 1.8551236749 & $2.38 \mathrm{E}-09$ \\
\hline GO:0033043 & Regulation of organelle organization & 42 & 1.8551236749 & $2.96 \mathrm{E}-09$ \\
\hline GO:0006605 & Protein targeting & 41 & 1.8109540636 & $5.08 \mathrm{E}-09$ \\
\hline GO:0032535 & Regulation of cellular component size & 41 & 1.8109540636 & 8.13E-09 \\
\hline GO:0006119 & Oxidative phosphorylation & 39 & 1.7226148410 & $9.12 \mathrm{E}-09$ \\
\hline GO:0043062 & Extracellular structure organization & 39 & 1.7226148410 & $1.14 \mathrm{E}-08$ \\
\hline GO:0016052 & Carbohydrate catabolic process & 38 & 1.6784452297 & $1.16 \mathrm{E}-08$ \\
\hline GO:0006754 & ATP biosynthetic process & 38 & 1.6784452297 & $1.21 \mathrm{E}-08$ \\
\hline GO:0006575 & Cellular amino acid derivative metabolic process & 38 & 1.6784452297 & 1.63E-08 \\
\hline GO:0019226 & Transmission of nerve impulse & 38 & 1.6784452297 & $3.36 \mathrm{E}-08$ \\
\hline GO:0007017 & Microtubule-based process & 37 & 1.6342756184 & 3.37E-08 \\
\hline GO:0009719 & Response to endogenous stimulus & 36 & 1.5901060071 & 4.09E-08 \\
\hline GO:0051493 & Regulation of cytoskeleton organization & 35 & 1.5459363958 & $6.21 \mathrm{E}-08$ \\
\hline GO:0046164 & Alcohol catabolic process & 34 & 1.5017667845 & $8.50 \mathrm{E}-08$ \\
\hline GO:0016053 & Organic acid biosynthetic process & 34 & 1.5017667845 & $1.21 \mathrm{E}-07$ \\
\hline GO:0046394 & Carboxylic acid biosynthetic process & 34 & 1.5017667845 & $1.21 \mathrm{E}-07$ \\
\hline GO:0010324 & Membrane invagination & 34 & 1.5017667845 & $1.42 \mathrm{E}-07$ \\
\hline GO:0006897 & Endocytosis & 34 & 1.5017667845 & $1.81 \mathrm{E}-07$ \\
\hline GO:0009725 & Response to hormone stimulus & 33 & 1.4575971731 & $1.85 \mathrm{E}-07$ \\
\hline GO:0007517 & Muscle organ development & 33 & 1.4575971731 & $3.23 \mathrm{E}-07$ \\
\hline GO:0055080 & Cation homeostasis & 33 & 1.4575971731 & 4.24E-07 \\
\hline GO:0044275 & Cellular carbohydrate catabolic process & 32 & 1.4134275618 & $7.66 \mathrm{E}-07$ \\
\hline GO:0008202 & Steroid metabolic process & 32 & 1.4134275618 & $1.18 \mathrm{E}-06$ \\
\hline GO:0007268 & Synaptic transmission & 32 & 1.4134275618 & $1.27 \mathrm{E}-06$ \\
\hline GO:0046395 & Carboxylic acid catabolic process & 30 & 1.3250883392 & $1.31 \mathrm{E}-06$ \\
\hline GO:0016054 & Organic acid catabolic process & 30 & 1.3250883392 & $1.31 \mathrm{E}-06$ \\
\hline GO:0044087 & Regulation of cellular component biogenesis & 30 & 1.3250883392 & $1.49 \mathrm{E}-06$ \\
\hline GO:0006979 & Response to oxidative stress & 29 & 1.2809187279 & $1.49 \mathrm{E}-06$ \\
\hline GO:0033365 & Protein localization in organelle & 29 & 1.2809187279 & $1.50 \mathrm{E}-06$ \\
\hline GO:0030198 & Extracellular matrix organization & 29 & 1.2809187279 & $1.50 \mathrm{E}-06$ \\
\hline
\end{tabular}


Table I. Continued.

\begin{tabular}{|c|c|c|c|c|}
\hline GO id. & Description & Count & $\%$ & $\mathrm{Q}<0.01$ \\
\hline GO:0043623 & Cellular protein complex assembly & 29 & 1.2809187279 & $1.50 \mathrm{E}-06$ \\
\hline GO:0055066 & Di-, trivalent inorganic cation homeostasis & 29 & 1.2809187279 & $1.65 \mathrm{E}-06$ \\
\hline GO:0015992 & Proton transport & 28 & 1.2367491166 & $2.14 \mathrm{E}-06$ \\
\hline GO:0019320 & Hexose catabolic process & 28 & 1.2367491166 & 2.24E-06 \\
\hline GO:0006007 & Glucose catabolic process & 28 & 1.2367491166 & $2.36 \mathrm{E}-06$ \\
\hline GO:0006818 & Hydrogen transport & 28 & 1.2367491166 & $2.42 \mathrm{E}-06$ \\
\hline GO:0046365 & Monosaccharide catabolic process & 28 & 1.2367491166 & $3.04 \mathrm{E}-06$ \\
\hline GO:0032956 & Regulation of actin cytoskeleton organization & 28 & 1.2367491166 & $3.40 \mathrm{E}-06$ \\
\hline GO:0032970 & Regulation of actin filament-based process & 28 & 1.2367491166 & $3.88 \mathrm{E}-06$ \\
\hline GO:0045454 & Cell redox homeostasis & 28 & 1.2367491166 & $4.20 \mathrm{E}-06$ \\
\hline GO:0006913 & Nucleocytoplasmic transport & 28 & 1.2367491166 & $4.55 \mathrm{E}-06$ \\
\hline GO:0051169 & Nuclear transport & 28 & 1.2367491166 & $6.02 \mathrm{E}-06$ \\
\hline GO:0051130 & Positive regulation of cellular component organization & 28 & 1.2367491166 & $6.58 \mathrm{E}-06$ \\
\hline GO:0016042 & Lipid catabolic process & 28 & 1.2367491166 & 7.04E-06 \\
\hline GO:0010608 & Post-transcriptional regulation of gene expression & 28 & 1.2367491166 & $8.39 \mathrm{E}-06$ \\
\hline GO:0030003 & Cellular cation homeostasis & 28 & 1.2367491166 & $9.47 \mathrm{E}-06$ \\
\hline GO:0015674 & Di-, trivalent inorganic cation transport & 28 & 1.2367491166 & $1.03 \mathrm{E}-05$ \\
\hline GO:0010035 & Response to inorganic substance & 27 & 1.1925795053 & $1.42 \mathrm{E}-05$ \\
\hline GO:0006790 & Sulfur metabolic process & 27 & 1.1925795053 & $1.43 \mathrm{E}-05$ \\
\hline GO:0006333 & Chromatin assembly or disassembly & 27 & 1.1925795053 & 2.23E-05 \\
\hline GO:0015986 & ATP synthesis coupled proton transport & 26 & 1.1484098940 & $2.39 \mathrm{E}-05$ \\
\hline GO:0015985 & $\begin{array}{l}\text { Energy coupled proton transport, down } \\
\text { electrochemical gradient }\end{array}$ & 26 & 1.1484098940 & $2.64 \mathrm{E}-05$ \\
\hline GO:0034220 & Ion transmembrane transport & 26 & 1.1484098940 & $2.89 \mathrm{E}-05$ \\
\hline GO:0008064 & $\begin{array}{l}\text { Regulation of actin polymerization or } \\
\text { depolymerization }\end{array}$ & 26 & 1.1484098940 & $4.22 \mathrm{E}-05$ \\
\hline GO:0030832 & Regulation of actin filament length & 26 & 1.1484098940 & 4.27E-05 \\
\hline GO:0043254 & Regulation of protein complex assembly & 26 & 1.1484098940 & $5.34 \mathrm{E}-05$ \\
\hline GO:0051129 & $\begin{array}{l}\text { Negative regulation of cellular component } \\
\text { organization }\end{array}$ & 26 & 1.1484098940 & $5.34 \mathrm{E}-05$ \\
\hline GO:0042692 & Muscle cell differentiation & 26 & 1.1484098940 & $5.49 \mathrm{E}-05$ \\
\hline GO:0060537 & Muscle tissue development & 26 & 1.1484098940 & $6.85 \mathrm{E}-05$ \\
\hline GO:0006511 & Ubiquitin-dependent protein catabolic process & 26 & 1.1484098940 & $7.99 \mathrm{E}-05$ \\
\hline GO:0006518 & Peptide metabolic process & 25 & 1.1042402827 & $8.11 \mathrm{E}-05$ \\
\hline GO:0032271 & Regulation of protein polymerization & 25 & 1.1042402827 & $8.43 \mathrm{E}-05$ \\
\hline GO:0014706 & Striated muscle tissue development & 25 & 1.1042402827 & $1.02 \mathrm{E}-04$ \\
\hline GO:0051050 & Positive regulation of transport & 25 & 1.1042402827 & $1.25 \mathrm{E}-04$ \\
\hline GO:0030005 & Cellular di-, tri-valent inorganic cation homeostasis & 25 & 1.1042402827 & $1.79 \mathrm{E}-04$ \\
\hline GO:0006323 & DNA packaging & 24 & 1.0600706714 & $1.90 \mathrm{E}-04$ \\
\hline GO:0042060 & Wound healing & 24 & 1.0600706714 & $1.91 \mathrm{E}-04$ \\
\hline GO:0006084 & Acetyl-CoA metabolic process & 23 & 1.0159010601 & $2.00 \mathrm{E}-04$ \\
\hline GO:0006096 & Glycolysis & 23 & 1.0159010601 & 2.24E-04 \\
\hline GO:0030833 & Regulation of actin filament polymerization & 23 & 1.0159010601 & 2.66E-04 \\
\hline GO:0006399 & tRNA metabolic process & 23 & 1.0159010601 & $2.72 \mathrm{E}-04$ \\
\hline GO:0051187 & Cofactor catabolic process & 22 & 0.9717314487 & $2.96 \mathrm{E}-04$ \\
\hline GO:0043244 & Regulation of protein complex disassembly & 22 & 0.9717314487 & 3.73E-04 \\
\hline GO:0031589 & Cell-substrate adhesion & 22 & 0.9717314487 & $4.24 \mathrm{E}-04$ \\
\hline GO:0051146 & Striated muscle cell differentiation & 22 & 0.9717314487 & 4.24E-04 \\
\hline GO:0051188 & Cofactor biosynthetic process & 22 & 0.9717314487 & 4.87E-04 \\
\hline GO:0007018 & Microtubule-based movement & 22 & 0.9717314487 & 4.87E-04 \\
\hline GO:0022904 & Respiratory electron transport chain & 21 & 0.9275618374 & 4.87E-04 \\
\hline GO:0009109 & Coenzyme catabolic process & 21 & 0.9275618374 & $5.98 \mathrm{E}-04$ \\
\hline
\end{tabular}


Table I. Continued.

\begin{tabular}{|c|c|c|c|c|}
\hline GO id. & Description & Count & $\%$ & $\mathrm{Q}<0.01$ \\
\hline GO:0015931 & $\begin{array}{l}\text { Nucleobase, nucleoside, nucleotide and } \\
\text { nucleic acid transport }\end{array}$ & 21 & 0.9275618374 & $6.05 \mathrm{E}-04$ \\
\hline GO:0031497 & Chromatin assembly & 21 & 0.9275618374 & 6.14E-04 \\
\hline GO:0065004 & Protein-DNA complex assembly & 21 & 0.9275618374 & $6.22 \mathrm{E}-04$ \\
\hline GO:0017038 & Protein import & 21 & 0.9275618374 & $6.40 \mathrm{E}-04$ \\
\hline GO:0050878 & Regulation of body fluid levels & 21 & 0.9275618374 & $6.65 \mathrm{E}-04$ \\
\hline GO:0005976 & Polysaccharide metabolic process & 21 & 0.9275618374 & $6.65 \mathrm{E}-04$ \\
\hline GO:0009060 & Aerobic respiration & 20 & 0.8833922261 & $6.65 \mathrm{E}-04$ \\
\hline GO:0006418 & tRNA aminoacylation for protein translation & 20 & 0.8833922261 & 8.53E-04 \\
\hline GO:0043039 & tRNA aminoacylation & 20 & 0.8833922261 & 8.84E-04 \\
\hline GO:0043038 & Amino acid activation & 20 & 0.8833922261 & 9.32E-04 \\
\hline GO:0007160 & Cell-matrix adhesion & 20 & 0.8833922261 & 9.32E-04 \\
\hline GO:0007015 & Actin filament organization & 20 & 0.8833922261 & $1.02 \mathrm{E}-03$ \\
\hline GO:0010639 & Negative regulation of organelle organization & 20 & 0.8833922261 & $1.13 \mathrm{E}-03$ \\
\hline GO:0050657 & Nucleic acid transport & 20 & 0.8833922261 & $1.13 \mathrm{E}-03$ \\
\hline GO:0051236 & Establishment of RNA localization & 20 & 0.8833922261 & $1.22 \mathrm{E}-03$ \\
\hline GO:0050658 & RNA transport & 20 & 0.8833922261 & $1.23 \mathrm{E}-03$ \\
\hline GO:0006403 & RNA localization & 20 & 0.8833922261 & $1.32 \mathrm{E}-03$ \\
\hline GO:0006334 & Nucleosome assembly & 20 & 0.8833922261 & $1.42 \mathrm{E}-03$ \\
\hline GO:0034728 & Nucleosome organization & 20 & 0.8833922261 & $1.45 \mathrm{E}-03$ \\
\hline GO:0006099 & Tricarboxylic acid cycle & 19 & 0.8392226148 & $1.46 \mathrm{E}-03$ \\
\hline GO:0046356 & Acetyl-CoA catabolic process & 19 & 0.8392226148 & $1.47 \mathrm{E}-03$ \\
\hline GO:0009064 & Glutamine family amino acid metabolic process & 19 & 0.8392226148 & $1.47 \mathrm{E}-03$ \\
\hline GO:0051494 & $\begin{array}{l}\text { Negative regulation of cytoskeleton } \\
\text { organization }\end{array}$ & 19 & 0.8392226148 & $1.71 \mathrm{E}-03$ \\
\hline GO:0019748 & Secondary metabolic process & 19 & 0.8392226148 & $1.84 \mathrm{E}-03$ \\
\hline GO:0030031 & Cell projection assembly & 19 & 0.8392226148 & $2.06 \mathrm{E}-03$ \\
\hline GO:0007599 & Hemostasis & 19 & 0.8392226148 & 2.06E-03 \\
\hline GO:0016125 & Sterol metabolic process & 19 & 0.8392226148 & 2.06E-03 \\
\hline GO:0006417 & Regulation of translation & 19 & 0.8392226148 & $2.06 \mathrm{E}-03$ \\
\hline GO:0043242 & $\begin{array}{l}\text { Negative regulation of protein complex } \\
\text { disassembly }\end{array}$ & 18 & 0.7950530035 & $2.06 \mathrm{E}-03$ \\
\hline GO:0006800 & $\begin{array}{l}\text { Oxygen and reactive oxygen species } \\
\text { metabolic process }\end{array}$ & 18 & 0.7950530035 & $2.16 \mathrm{E}-03$ \\
\hline GO:0048193 & Golgi vesicle transport & 18 & 0.7950530035 & $2.26 \mathrm{E}-03$ \\
\hline GO:0051028 & mRNA transport & 18 & 0.7950530035 & 2.33E-03 \\
\hline GO:0008203 & Cholesterol metabolic process & 18 & 0.7950530035 & 2.34E-03 \\
\hline GO:0007596 & Blood coagulation & 18 & 0.7950530035 & $2.44 \mathrm{E}-03$ \\
\hline GO:0050817 & Coagulation & 18 & 0.7950530035 & 2.73E-03 \\
\hline GO:0002526 & Acute inflammatory response & 18 & 0.7950530035 & 2.78E-03 \\
\hline GO:0042493 & Response to drug & 18 & 0.7950530035 & 2.84E-03 \\
\hline GO:0006749 & Glutathione metabolic process & 17 & 0.7508833922 & 2.86E-03 \\
\hline GO:0030834 & Regulation of actin filament depolymerization & 17 & 0.7508833922 & 2.86E-03 \\
\hline GO:0044242 & Cellular lipid catabolic process & 17 & 0.7508833922 & $3.04 \mathrm{E}-03$ \\
\hline GO:0051170 & Nuclear import & 17 & 0.7508833922 & $3.19 \mathrm{E}-03$ \\
\hline GO:0055001 & Muscle cell development & 17 & 0.7508833922 & $3.26 \mathrm{E}-03$ \\
\hline GO:0009310 & Amine catabolic process & 17 & 0.7508833922 & 3.28E-03 \\
\hline GO:0009309 & Amine biosynthetic process & 17 & 0.7508833922 & 3.34E-03 \\
\hline GO:0051248 & Negative regulation of protein metabolic process & 17 & 0.7508833922 & 3.34E-03 \\
\hline GO:0006633 & Fatty acid biosynthetic process & 17 & 0.7508833922 & 3.34E-03 \\
\hline GO:0060627 & Regulation of vesicle-mediated transport & 17 & 0.7508833922 & $3.77 \mathrm{E}-03$ \\
\hline GO:0009791 & Post-embryonic development & 17 & 0.7508833922 & 3.99E-03 \\
\hline
\end{tabular}


Table I. Continued.

\begin{tabular}{llccc}
\hline GO id. & \multicolumn{1}{c}{ Description } & Count & $\%$ & Q<0.01 \\
\hline GO:0018130 & Heterocycle biosynthetic process & 16 & 0.7067137809 & $4.28 \mathrm{E}-03$ \\
GO:0055002 & Striated muscle cell development & 16 & 0.7067137809 & $4.35 \mathrm{E}-03$ \\
GO:0034504 & Protein localization in nucleus & 16 & 0.7067137809 & $4.53 \mathrm{E}-03$ \\
GO:0032269 & Negative regulation of cellular protein & 16 & 0.7067137809 & $5.12 \mathrm{E}-03$ \\
& metabolic process & & & \\
GO:0002449 & Lymphocyte mediated immunity & 16 & 0.7067137809 & $5.13 \mathrm{E}-03$ \\
GO:0030835 & Negative regulation of actin filament & 15 & 0.6625441696 & $5.13 \mathrm{E}-03$ \\
& depolymerization & 15 & 0.6625441696 & $5.25 \mathrm{E}-03$ \\
GO:0032272 & Negative regulation of protein polymerization & 15 & 0.6625441696 & $5.46 \mathrm{E}-03$ \\
GO:0031333 & Negative regulation of protein complex assembly & 15 & 0.6625441696 & $5.56 \mathrm{E}-03$ \\
GO:0000302 & Response to reactive oxygen species & 15 & 0.6625441696 & $5.56 \mathrm{E}-03$ \\
GO:0051258 & Protein polymerization & 15 & 0.6625441696 & $5.56 \mathrm{E}-03$ \\
GO:0009063 & Cellular amino acid catabolic process & 15 & 0.6625441696 & $6.69 \mathrm{E}-03$ \\
GO:0006606 & Protein import into nucleus & 15 & 0.6625441696 & $6.69 \mathrm{E}-03$ \\
GO:0070482 & Response to oxygen levels & 15 & 0.6625441696 & $6.69 \mathrm{E}-03$ \\
GO:0006694 & Steroid biosynthetic process & 14 & 0.6183745583 & $6.74 \mathrm{E}-03$ \\
GO:0042773 & ATP synthesis coupled electron transport & 14 & 0.6183745583 & $7.11 \mathrm{E}-03$ \\
GO:0051693 & Actin filament capping & 14 & 0.6183745583 & $7.27 \mathrm{E}-039$ \\
GO:0042743 & Hydrogen peroxide metabolic process & 14 & 0.6183745583 & $7.31 \mathrm{E}-03$ \\
GO:0034599 & Cellular response to oxidative stress & 14 & 0.6183745583 & $8.12 \mathrm{E}-03$ \\
GO:0042542 & Response to hydrogen peroxide & 14 & 0.6183745583 & $8.13 \mathrm{E}-03$ \\
GO:0030837 & Negative regulation of actin filament & & & \\
& polymerization & 14 & 0.6183745583 & $8.55 \mathrm{E}-03$ \\
GO:0034330 & Cell junction organization & 14 & 0.6183745583 & $8.62 \mathrm{E}-03$ \\
GO:0006413 & Translational initiation & 0.6183745583 & $8.74 \mathrm{E}-03$ \\
GO:0008652 & Cellular amino acid biosynthetic process & 0.6183745583 & $9.32 \mathrm{E}-03$ \\
GO:0006997 & Nucleus organization & & & \\
\hline
\end{tabular}

$\mathrm{Q}$, value calculated from p-value by Benjamini-Hochberg-Yekutieli multiple testing correction with Fisher discriminant analysis.

experiments. We found that the peptide spectral intensity is higher than the spectral counts in the quantification of proteomic analysis. The average peptide spectral intensity was used as a standard for the relative quantification of proteins. A total of 2,331 proteins were identified by using the sequenced peptides as queries in searches against the IPI mouse database. Repeating the search against the related decoy database with the same parameters yielded a low (1\%) false discovery rate (FDR) at the peptide level, indicating that our approach has high specificity.

Enriched pathways and functional categories. Among the 2,331 identified proteins, 2,287 were found to correspond to unique genes. To characterize these proteins, we initially categorized them based on biological process terms of GO and conducted an enrichment analysis. The most significant categories are shown in Table I. These processes include the generation of precursor metabolites and energy (504), translation and protein targeting (343), nucleotide and nucleic acid metabolism (298), transport (275) and cellular component organization (289). Some of the identified proteins were associated with cytoskeleton organization (183), protein degradation (116) or response to stimulus (115). Approximately 164 proteins with unknown functions were also identified in the proteome of round spermatids. The full classification of the unknown-function proteins with regards to the biological processes they are associated with is demonstrated in a pie chart in Fig. 2.

Furthermore, the predicted molecular function and subcellular localization of the identified proteins was retrieved from GO and enrichment analysis was performed with DAVID tools. A total of 1,818 identified proteins were classified into 9 groups according to their molecular function: binding (866); catalytic activity (400); structural molecule activity (155); motor activity (150); translation regulator activity (35); anti-oxidant activity (19); and enzyme inhibitor activity (43). The full classification of 1,818 proteins is shown in a pie chart in Fig. 3.

Fig. 4 shows the classification of the proteins identified in this study according to their predicted subcellular localization. If an individual protein was predicted to localize in more than one cellular compartment, all localizations were counted nonexclusively. The largest proportion of the identified proteins was associated with the mitochondrion (486), followed by the following cell parts/organelles: cytoplasm (327); cytoskeleton (227); endoplasmic reticulum (260); nucleus (194); Golgi apparatus (151); membrane (148); and lysosome (45). 

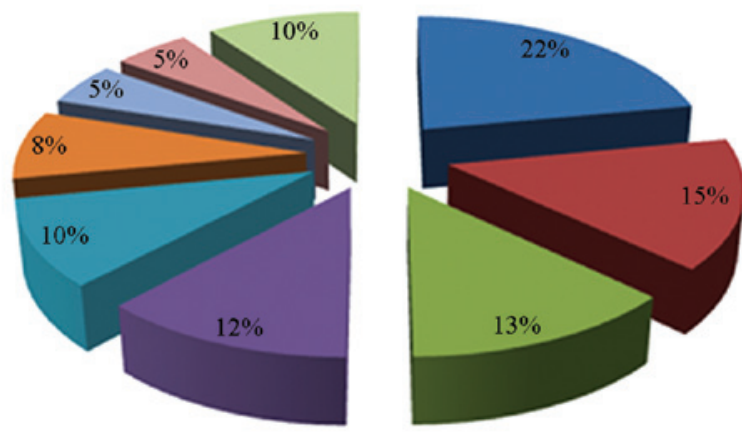

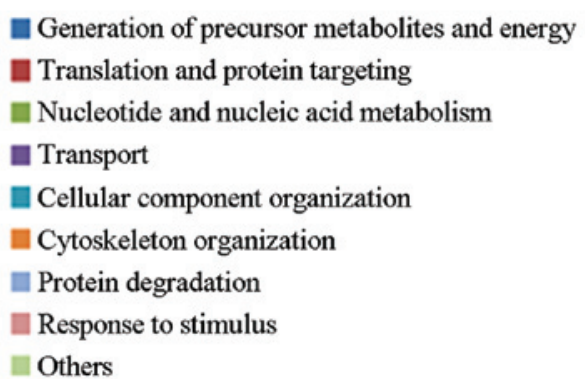

Figure 2. Classification of identified proteins based on relevant biological processes (Gene Ontology terms).

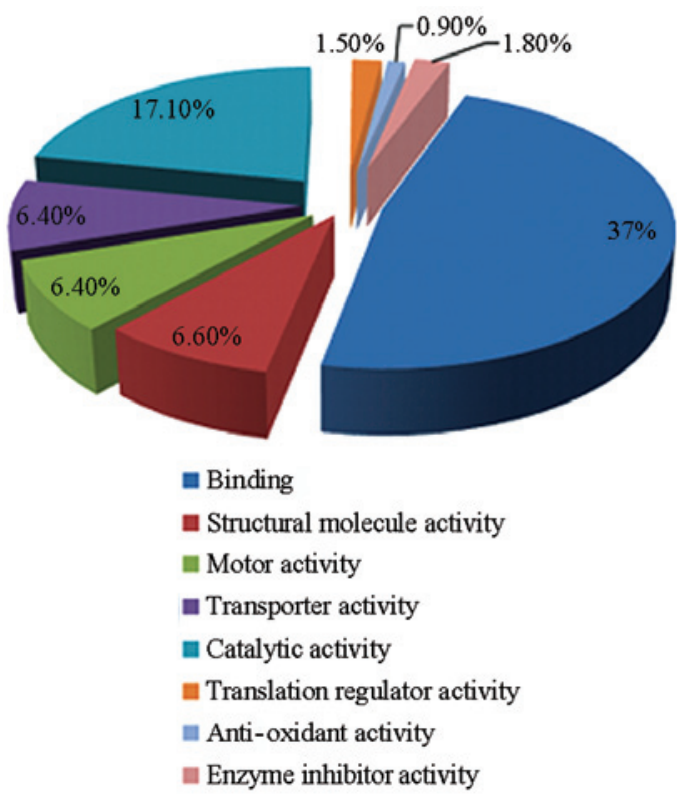

Figure 3. Classification of identified proteins based on relevant molecular functions (Gene Ontology terms).

To investigate the pathways governing the behavior of round spermatids, we further classified the proteins based on KEGG pathway terms. As expected, an important proportion of the identified proteins (370) were involved in metabolic pathways. Among these proteins, 81 were involved in the oxidative phosphorylation pathway (Fig. 5A) that supports spermatid maturation, and 34 were related to the fatty acid metabolism pathway. This pathway provides the necessary energy for spermatid maturation. In addition, 27 proteins were bound to the citric acid (TCA) cycle (Fig. 5B) and 92 proteins were involved in sugar metabolism pathways, such as glycolysis, gluconeogenesis, pyruvate metabolism,

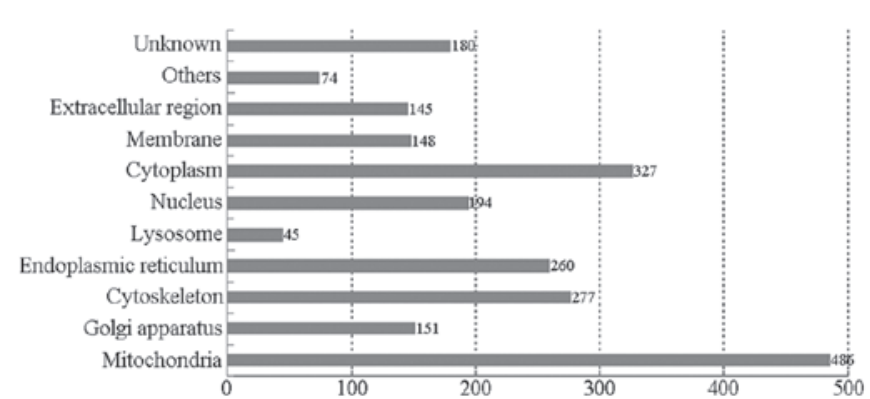

Figure 4. Subcellular localization of identified proteins (DAVID graph).

starch and sucrose metabolism and the pentose phosphate pathway (data not shown).

In addition to the proteins involved in metabolism, a large group of proteins essential for translation were identified in round spermatids. A total of 68 proteins were annotated as parts of the ribosomal pathway, and 17 proteins as related to aminoacyl-tRNA biosynthesis. Numerous proteins were also involved in protein degradation. We found that the round spermatid proteome contained 28 proteins in the proteasome pathway and 40 proteins in the lysosome pathway (Fig. 6A and B). Pathway annotation of the haploid proteome by the Pathway Studio software (http:// www.elsevier.com/online-tools/pathway-studio/pathway-studioweb) revealed that 60 proteins are components of the spliceosome pathway, in which heterogeneous nuclear RNA (hnRNA) is converted to mRNA (Fig. 7).

Numerous actin and actin-binding proteins participate in the formation of sperm. LC-MS/MS analysis performed in this study identified $\sim 94$ actin-binding proteins, involved in the regulation of the actin cytoskeleton KEGG pathway in round spermatids of mice (Fig. 8A and B).

A total of 25 proteins involved in gap junctions, 44 proteins in tight junctions and 26 proteins in adherens junctions were also detected. Seven proteins involved in the nucleocytoplasmic transport pathway (Fig. 9) and nine proteins related to the caspase cascade of the apoptotic signaling pathway were also identified. Full results from the pathway analysis are shown in Table II.

\section{Discussion}

The proteome of a cell or an organelle provides information regarding the ensemble of proteins expressed in that particular cell or organelle, and the modification of proteins under specific physiological conditions and time points (21). Label-free proteomics is a rapidly growing MS-based quantitative proteomic workflow, since it does not require chemical labeling; quantification is thus unaffected by labelling efficiencies (22). In order to fully characterise spermiogenesis, and in particular the biological characteristics of round spermatids, we obtained, using a label-free proteomic approach, the full proteome of 2,331 proteins of round spermatids of mice; among these proteins, 2,287 mapped to unique genes.

Spermatogenesis is a complex and highly ordered process, which begins with the differentiation of spermatogonial stem cells and ends with the formation of mature sperm. In haploid germ cell differentiation (or spermiogenesis), round spermatids undergo marked morphological changes. The nucleus 
A
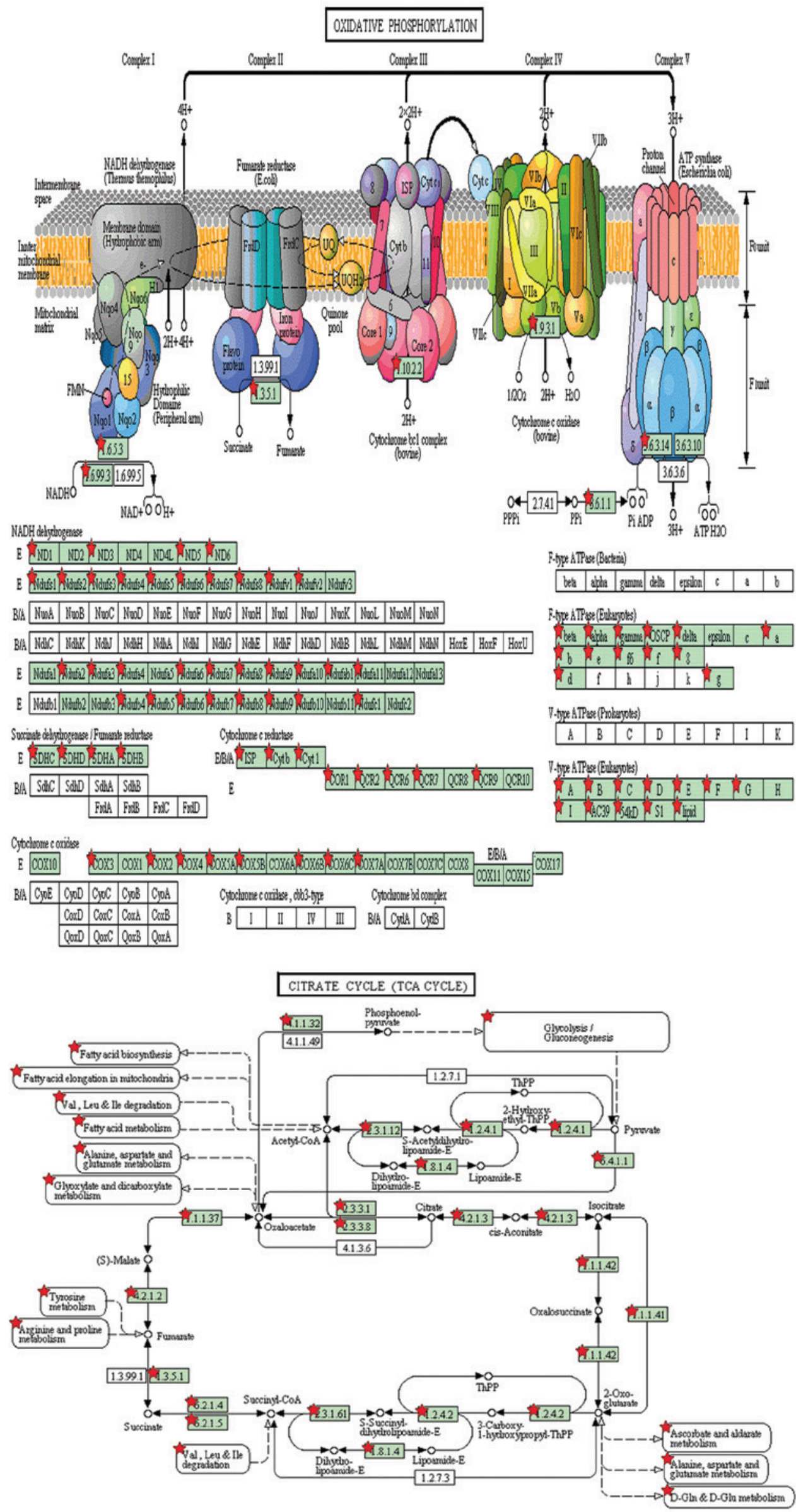

Figure 5. Pathway analysis using the Kyoto Encyclopedia of Genes and Genomes (KEGG) Pathway database. Proteins involved in the (A) oxidative phosphorylation pathway $(\mathrm{n}=81)$ and $(\mathrm{B})$ the citrate $(\mathrm{TCA})$ cycle $(\mathrm{n}=27)$. Red stars denote the detected proteins. 
A

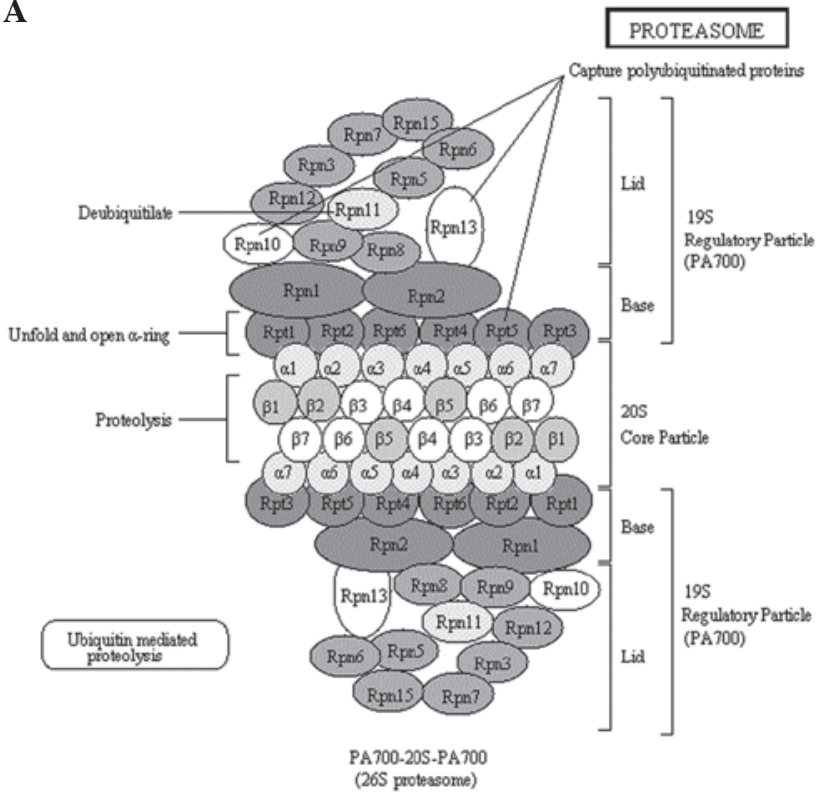

Regulatory Particles

Formation of immunoproteasomes

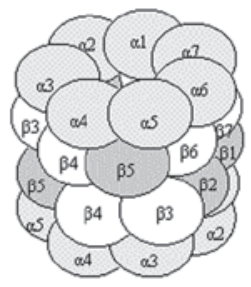

IFNy

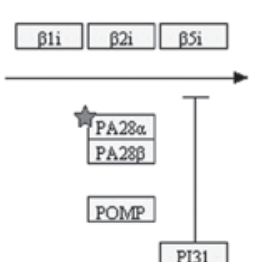

B

Standard $20 \mathrm{~S}$ proteasome

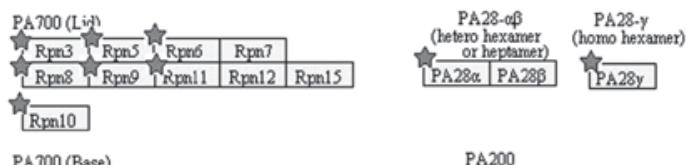

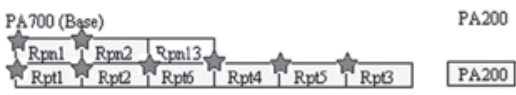

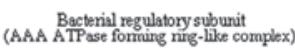

Archseal regulatory suburit
(oligomelic cornplex)

ARC

PAN

Core Particles (20S proteasome)

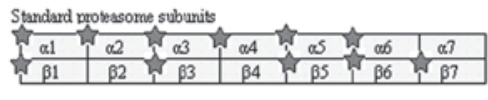

Immunoproteasome suburits Thymoproteasome suburits

$\beta 1 i \quad \beta 2 i \quad \beta 5 i$

Prokaryotic 20S suburits

\begin{tabular}{|l|}
\hline$\alpha$ \\
\hline$\beta$ \\
\hline
\end{tabular}
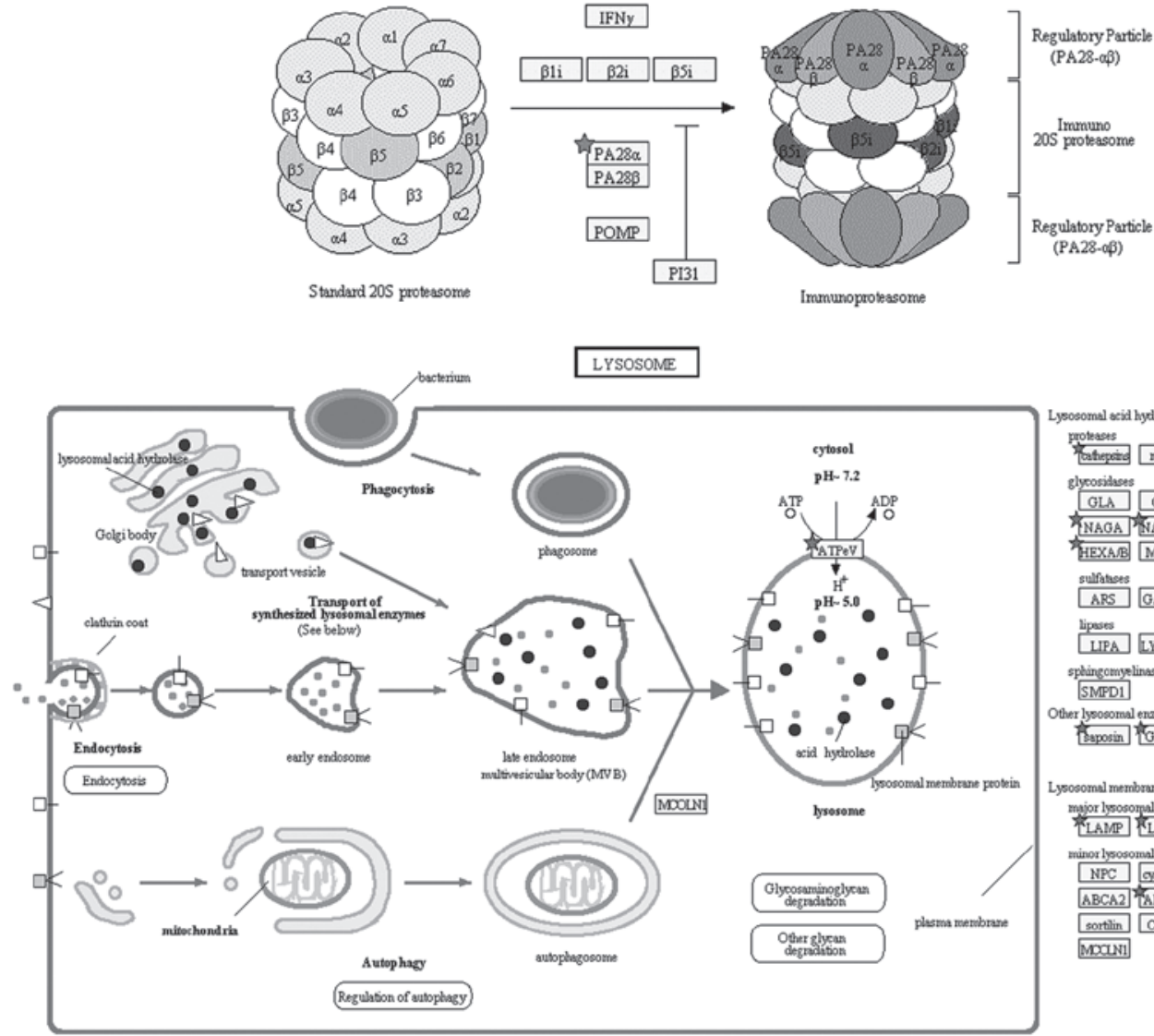

Lyosomal sexid hydroheses

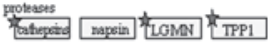

1)

W

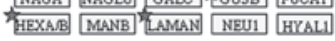

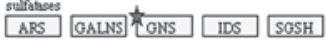

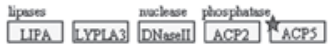

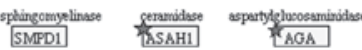

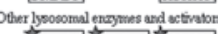

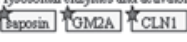

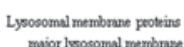

Tinis]

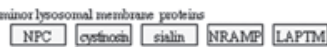

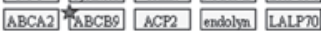

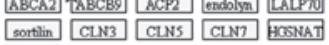

Mast

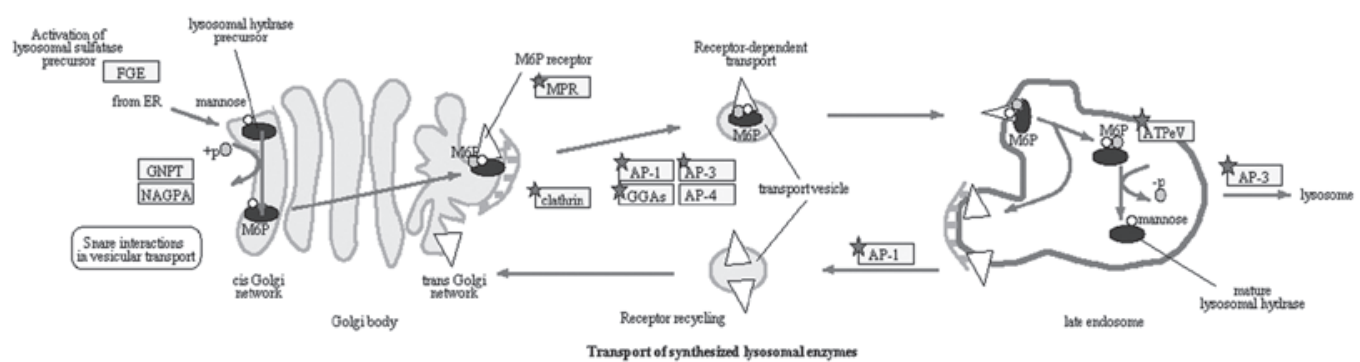

Figure 6. Pathway analysis using the Kyoto Encyclopedia of Genes and Genomes (KEGG) Pathway database. Proteins involved in the (A) proteasome pathway $(n=28)$ and $(B)$ the lysosome pathway $(n=40)$. Stars denote the detected proteins. 


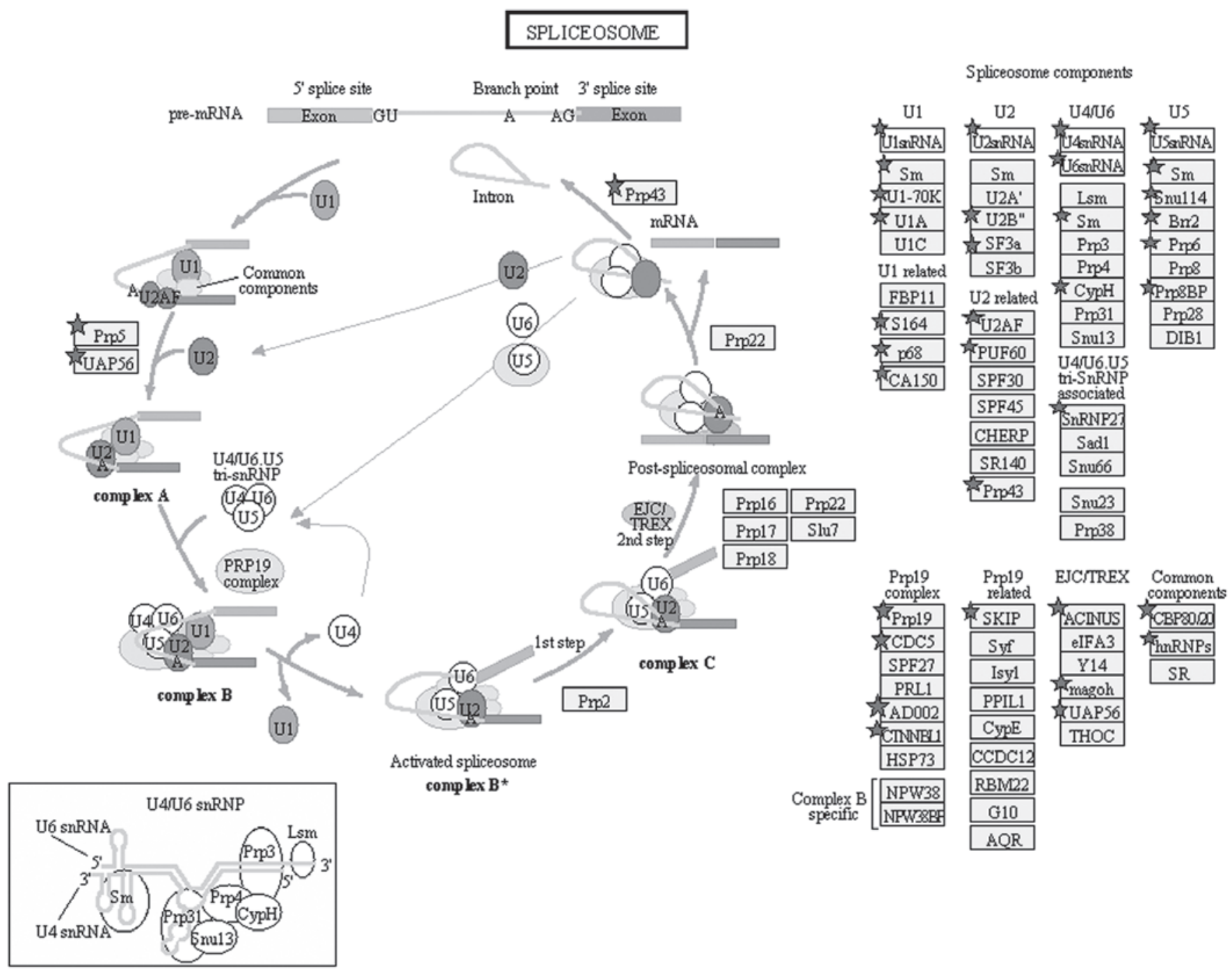

Figure 7. Pathway analysis using the Kyoto Encyclopedia of Genes and Genomes (KEGG) Pathway database. Proteins involved in the spliceosome pathway $(n=60)$ are shown. Stars denote the detected proteins.

becomes more compact, the mitochondria are rearranged, the flagellum develops and an acrosome is formed (23). In the present study, $\beta$-1-globin, $\beta$-2-globin and histone $\mathrm{H} 4$ were found to be expressed in round spermatids (data not shown). These proteins are constituents of the chromatin structure and participate in gene regulation (24).

Energy metabolism is a key process for the development of round spermatids. Round spermatids require ATP, most probably to sustain morphological changes, as well as active protein degradation and synthesis. In round spermatids, lactate and pyruvate are the preferred substrates for the generation of energy; the use of glucose is limited (25). In our study, 504 proteins were identified as involved in the generation of precursor metabolites and energy (Table I). The TCA cycle is the main energy resource of round spermatids, although glycolytic and pentose phosphate pathways also contribute to energy production in the spermatids (26). Citrate synthase, isocitrate dehydrogenase and $\alpha$-oxoglutarate dehydrogenase are expressed in round spermatids (Table I and Fig. 5B). L-lactate dehydrogenase, pyruvate kinase and pyruvate dehydrogenase, which are involved in the glycolytic pathway, are also expressed in round spermatids. Pyruvate kinase is fully activated in round spermatids when glucose is metabolized by the glycolytic pathway (27). A total of 81 proteins were identified as involved in the oxidative phosphorylation pathway in round spermatids (Fig. 5A); these proteins may be involved in the formation and in reactions occurring in the acrosome, which require energy provided by oxidative phosphorylation (25).

At the stage of development of round spermatids, numerous proteins and organelles are degraded; the ubiquitin-proteasome and the lysosome pathways are important, particularly in facilitating the formation of condensed sperms. In the present study, 28 proteins were found as involved in the proteasome pathway and 40 proteins in the lysosome pathway (Fig. 6A and B). Post-translational protein modification by ubiquitination is a signal for lysosomal or proteasomal proteolysis. UBA6 is an E1-activating enzyme, which can activate ubiquitin and FAT10 $(28,29)$. UBA6 uses a specific E2 enzyme, namely, Use1, which cooperates with E3 enzymes to ubiquitylate a unique subset of protein substrates (30). CUL4 is an E3 ubiquitin ligase; in the absence of a functional CUL4 gene, a decreased number of spermatozoa, reduced sperm motility and defective acrosome formation are observed (31). The ubiquitination of proteins can be regulated and reversed by deubiquitinating enzymes. 
A

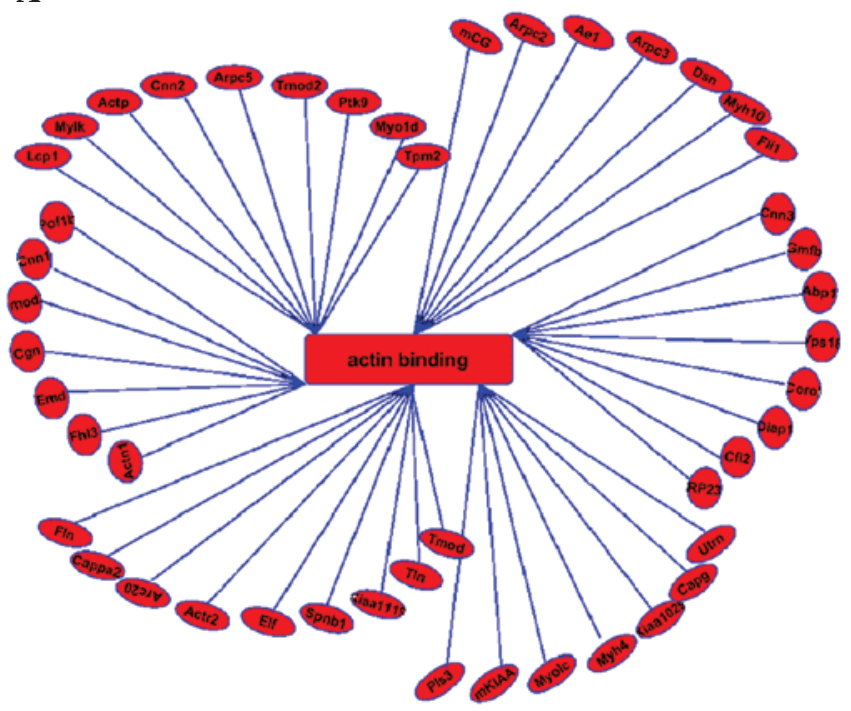

B

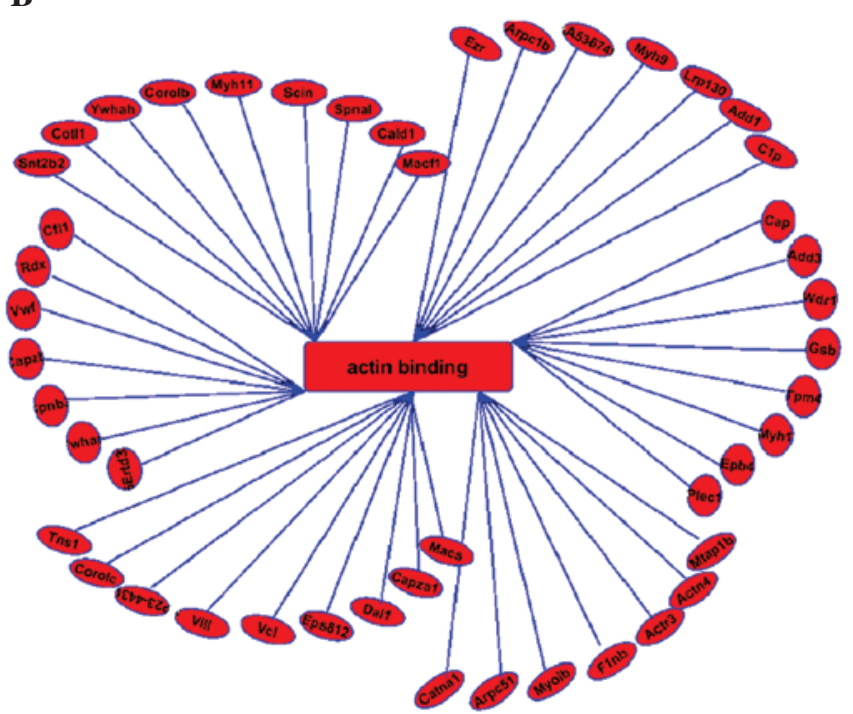

Figure 8. Pathway analysis using the Kyoto Encyclopedia of Genes and Genomes (KEGG) Pathway database. Proteins involved in regulation of the actin cytoskeleton (actin-binding) are shown $(\mathrm{n}=94)$.

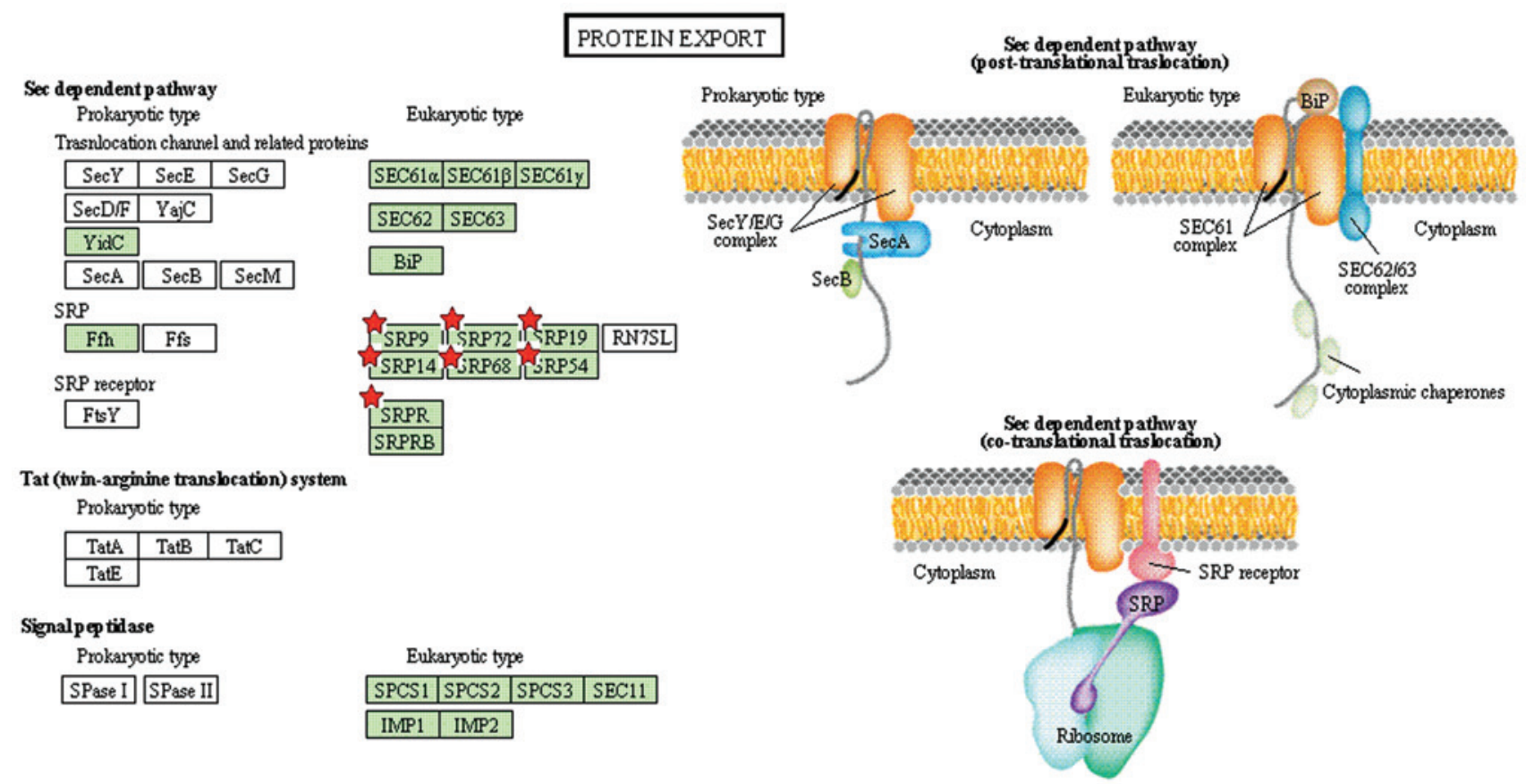

Figure 9. Pathway analysis using the Kyoto Encyclopedia of Genes and Genomes (KEGG) Pathway database. Proteins participating in the nucleocytoplasmic transport pathway $(n=7)$ are shown. Red stars denote the detected proteins.

Ubiquitin C-terminal hydrolases (UCHs) are responsible for the removal of polyubiquitin chains during substrate priming for proteasomal proteolysis. UCHL1 and UCHL3, which were identified in round spermatids in our study, are involved in sperm acrosomal formation and function; these enzymes are known to be important for fertilization $(32,33)$.

Transcription during spermatogenesis begins in almost-round spermatids; these transcripts are then translated during spermatid elongation and acrosome formation $(34,35)$. In our study, 60 proteins were annotated as parts of the spliceosome pathway, in which hnRNA is converted to mRNA and translated to proteins (Fig. 7). Following protein synthesis, some proteins are translocated between the nuclear and cytoplasmic compartments to allow the essential cellular responses to extracellular and intracellular signals. In our study, seven proteins, such as SRP19 and SRP72, were identified as involved in protein transport and regulation of signal transduction $(36,37)$.

Acrosome formation and spermatid nuclear shaping are two major processes of spermiogenesis. Actin and actin-binding proteins are implicated in various aspects, including acrosome formation and nuclear shaping of the spermatids during spermiogenesis. Actin is also involved in germ cell movement, protein transport and nuclear modifications. Numerous actin-binding proteins are found in actin-rich sites, and these 
Table II. Pathway analysis in the round spermatid proteome using the Kyoto Encyclopedia of Genes and Genomes (KEGG) and the BioCarta Pathway databases.

\begin{tabular}{|c|c|c|c|c|c|}
\hline Source & Term & Count & $\%$ & $\mathrm{P}$ & $\mathrm{Q}^{\mathrm{a}}$ \\
\hline KEGG & Ribosome & 68 & 3.0 & $6.5 \mathrm{E}-32$ & $1.2 \mathrm{E}-29$ \\
\hline KEGG & Oxidative phosphorylation & 81 & 3.6 & $3.2 \mathrm{E}-28$ & $2.9 \mathrm{E}-26$ \\
\hline KEGG & Parkinson's disease & 73 & 3.2 & $6.9 \mathrm{E}-21$ & 4.2E-19 \\
\hline KEGG & Alzheimer's disease & 85 & 3.8 & $2.1 \mathrm{E}-18$ & $9.6 \mathrm{E}-17$ \\
\hline KEGG & $\begin{array}{l}\text { Valine, leucine and isoleucine } \\
\text { degradation }\end{array}$ & 36 & 1.6 & $1.9 \mathrm{E}-17$ & $7.0 \mathrm{E}-16$ \\
\hline KEGG & Huntington's disease & 83 & 3.7 & $4.8 \mathrm{E}-17$ & $1.5 \mathrm{E}-15$ \\
\hline KEGG & Fatty acid metabolism & 34 & 1.5 & $1.1 \mathrm{E}-15$ & $2.9 \mathrm{E}-14$ \\
\hline KEGG & Citrate (TCA) cycle & 27 & 1.2 & $4.2 \mathrm{E}-15$ & $9.8 \mathrm{E}-14$ \\
\hline KEGG & Spliceosome & 60 & 2.7 & $6.8 \mathrm{E}-14$ & $1.4 \mathrm{E}-12$ \\
\hline KEGG & Glycolysis/Gluconeogenesis & 38 & 1.7 & $2.3 \mathrm{E}-11$ & 4.3E-10 \\
\hline KEGG & Propanoate metabolism & 23 & 1.0 & $7.5 \mathrm{E}-11$ & $1.3 \mathrm{E}-9$ \\
\hline KEGG & Glutathione metabolism & 30 & 1.3 & $1.6 \mathrm{E}-9$ & $2.5 \mathrm{E}-8$ \\
\hline KEGG & Proteasome & 28 & 1.2 & 2.4E-9 & $3.5 \mathrm{E}-8$ \\
\hline KEGG & Pyruvate metabolism & 25 & 1.1 & $1.1 \mathrm{E}-8$ & $1.5 \mathrm{E}-7$ \\
\hline KEGG & Focal adhesion & 66 & 2.9 & $5.7 \mathrm{E}-7$ & $7.0 \mathrm{E}-6$ \\
\hline KEGG & Butanoate metabolism & 21 & 0.9 & $1.1 \mathrm{E}-6$ & $1.3 \mathrm{E}-5$ \\
\hline KEGG & ECM-receptor interaction & 35 & 1.5 & $1.3 \mathrm{E}-6$ & $1.4 \mathrm{E}-5$ \\
\hline KEGG & Drug metabolism & 31 & 1.4 & $9.6 \mathrm{E}-6$ & $9.9 \mathrm{E}-5$ \\
\hline KEGG & PPAR signaling pathway & 32 & 1.4 & $1.1 \mathrm{E}-5$ & $1.1 \mathrm{E}-4$ \\
\hline KEGG & Arginine/proline metabolism & 24 & 1.1 & $2.2 \mathrm{E}-5$ & 2.1E-4 \\
\hline KEGG & Tight junction & 44 & 1.9 & $1.0 \mathrm{E}-4$ & $9.2 \mathrm{E}-4$ \\
\hline KEGG & Lysosome & 40 & 1.8 & $1.1 \mathrm{E}-4$ & $9.2 \mathrm{E}-4$ \\
\hline KEGG & $\begin{array}{l}\text { Metabolism of xenobiotics by P450 } \\
\text { cytochrome }\end{array}$ & 26 & 1.1 & $1.5 \mathrm{E}-4$ & $1.2 \mathrm{E}-3$ \\
\hline KEGG & $\beta$-alanine metabolism & 13 & 0.6 & $1.5 \mathrm{E}-4$ & $1.2 \mathrm{E}-3$ \\
\hline KEGG & Tryptophan metabolism & 18 & 0.8 & $3.5 \mathrm{E}-4$ & $2.6 \mathrm{E}-3$ \\
\hline KEGG & $\begin{array}{l}\text { Alanine, aspartate and glutamate } \\
\text { metabolism }\end{array}$ & 15 & 0.7 & $3.7 \mathrm{E}-4$ & $2.6 \mathrm{E}-3$ \\
\hline KEGG & Protein export & 7 & 0.3 & 7.7E-4 & $5.3 \mathrm{E}-3$ \\
\hline KEGG & Fatty acid elongation in mitochondria & 7 & 0.3 & 7.7E-4 & $5.3 \mathrm{E}-3$ \\
\hline KEGG & Starch and sucrose metabolism & 16 & 0.7 & $1.0 \mathrm{E}-3$ & $6.6 \mathrm{E}-3$ \\
\hline KEGG & Pentose phosphate pathway & 13 & 0.6 & $1.1 \mathrm{E}-3$ & $6.9 \mathrm{E}-3$ \\
\hline KEGG & Leukocyte transendothelial migration & 37 & 1.6 & $1.1 \mathrm{E}-3$ & $6.8 \mathrm{E}-3$ \\
\hline KEGG & Cardiac muscle contraction & 27 & 1.2 & $1.1 \mathrm{E}-3$ & $6.7 \mathrm{E}-3$ \\
\hline KEGG & $\begin{array}{l}\text { Valine, leucine and isoleucine } \\
\text { biosynthesis }\end{array}$ & 8 & 0.4 & $1.2 \mathrm{E}-3$ & $6.8 \mathrm{E}-3$ \\
\hline KEGG & Porphyrin and chlorophyll metabolism & 14 & 0.6 & $1.4 \mathrm{E}-3$ & $7.9 \mathrm{E}-3$ \\
\hline KEGG & Adherens junction & 26 & 1.1 & $1.7 \mathrm{E}-3$ & $9.3 \mathrm{E}-3$ \\
\hline KEGG & Aminoacyl-tRNA biosynthesis & 17 & 0.8 & $2.1 \mathrm{E}-3$ & $1.1 \mathrm{E}-2$ \\
\hline KEGG & Galactose metabolism & 12 & 0.5 & $5.8 \mathrm{E}-3$ & $2.9 \mathrm{E}-2$ \\
\hline KEGG & Regulation of actin cytoskeleton & 56 & 2.5 & $6.2 \mathrm{E}-3$ & $3.0 \mathrm{E}-2$ \\
\hline KEGG & $\begin{array}{l}\text { Pentose and glucuronate } \\
\text { interconversions }\end{array}$ & 9 & 0.4 & $6.5 \mathrm{E}-3$ & $3.1 \mathrm{E}-2$ \\
\hline KEGG & $\begin{array}{l}\text { Arrhythmogenic right ventricular } \\
\text { cardiomyopathy }\end{array}$ & 24 & 1.1 & $6.9 \mathrm{E}-3$ & $3.2 \mathrm{E}-2$ \\
\hline KEGG & $\begin{array}{l}\text { Amino sugar and nucleotide sugar } \\
\text { metabolism }\end{array}$ & 16 & 0.7 & $9.6 \mathrm{E}-3$ & 4.4E-2 \\
\hline KEGG & Limonene and pinene degradation & 8 & 0.4 & $1.2 \mathrm{E}-2$ & $5.1 \mathrm{E}-2$ \\
\hline KEGG & Ascorbate and aldarate metabolism & 8 & 0.4 & $1.2 \mathrm{E}-2$ & $5.1 \mathrm{E}-2$ \\
\hline
\end{tabular}


Table II. Continued.

\begin{tabular}{|c|c|c|c|c|c|}
\hline Source & Term & Count & $\%$ & $\mathrm{P}$ & $\mathrm{Q}^{\mathrm{a}}$ \\
\hline KEGG & Phenylalanine metabolism & 10 & 0.4 & $1.2 \mathrm{E}-2$ & $5.1 \mathrm{E}-2$ \\
\hline KEGG & Long-term potentiation & 22 & 1.0 & $1.2 \mathrm{E}-2$ & $5.2 \mathrm{E}-2$ \\
\hline KEGG & Fc $\gamma$ R-mediated phagocytosis & 28 & 1.2 & $1.7 \mathrm{E}-2$ & $6.8 \mathrm{E}-2$ \\
\hline KEGG & Glyoxylate and dicarboxylate metabolism & 8 & 0.4 & $1.7 \mathrm{E}-2$ & $6.9 \mathrm{E}-2$ \\
\hline KEGG & Tyrosine metabolism & 14 & 0.6 & 1.9E-2 & 7.3E-2 \\
\hline KEGG & Gap junction & 25 & 1.1 & $2.0 \mathrm{E}-2$ & 7.5E-2 \\
\hline KEGG & Synthesis and degradation of ketone bodies & 6 & 0.3 & $2.3 \mathrm{E}-2$ & 8.7E-2 \\
\hline KEGG & Lysine degradation & 14 & 0.6 & $2.8 \mathrm{E}-2$ & $1.0 \mathrm{E}-1$ \\
\hline KEGG & N-glycan biosynthesis & 15 & 0.7 & $3.3 \mathrm{E}-2$ & $1.2 \mathrm{E}-1$ \\
\hline KEGG & Prion diseases & 12 & 0.5 & $4.5 \mathrm{E}-2$ & $1.5 \mathrm{E}-1$ \\
\hline KEGG & Long-term depression & 20 & 0.9 & $6.0 \mathrm{E}-2$ & $2.0 \mathrm{E}-1$ \\
\hline KEGG & Fructose and mannose metabolism & 12 & 0.5 & $6.5 \mathrm{E}-2$ & $2.1 \mathrm{E}-1$ \\
\hline KEGG & Oocyte meiosis & 29 & 1.3 & $6.7 \mathrm{E}-2$ & $2.1 \mathrm{E}-1$ \\
\hline KEGG & Renin-angiotensin system & 7 & 0.3 & $9.7 \mathrm{E}-2$ & $2.9 \mathrm{E}-1$ \\
\hline BioCarta & $\begin{array}{l}\text { Shuttle for transfer of acetyl groups from } \\
\text { mitochondria to the cytosol }\end{array}$ & 8 & 0.4 & $7.9 \mathrm{E}-5$ & $1.7 \mathrm{E}-2$ \\
\hline BioCarta & uCalpain and friends in cell spread & 8 & 0.4 & $3.7 \mathrm{E}-3$ & $3.3 \mathrm{E}-1$ \\
\hline BioCarta & ERAD pathway & 9 & 0.4 & $6.6 \mathrm{E}-3$ & $3.8 \mathrm{E}-1$ \\
\hline BioCarta & $\begin{array}{l}\text { AKAP95 role in mitosis and chromosome } \\
\text { dynamics }\end{array}$ & 6 & 0.3 & $1.9 \mathrm{E}-2$ & $6.4 \mathrm{E}-1$ \\
\hline BioCarta & Agrin in postsynaptic differentiation & 11 & 0.5 & $2.2 \mathrm{E}-2$ & $6.1 \mathrm{E}-1$ \\
\hline BioCarta & $\begin{array}{l}\text { Cycling of Ran in nucleocytoplasmic } \\
\text { transport }\end{array}$ & 4 & 0.2 & $2.7 \mathrm{E}-2$ & $6.2 \mathrm{E}-1$ \\
\hline BioCarta & Protein kinase $\mathrm{A}$ at the centrosome & 7 & 0.3 & $2.9 \mathrm{E}-2$ & $6.0 \mathrm{E}-1$ \\
\hline BioCarta & Caspase cascade in apoptosis & 9 & 0.4 & $4.1 \mathrm{E}-2$ & $6.8 \mathrm{E}-1$ \\
\hline BioCarta & $\begin{array}{l}\text { Endocytotic role of NDK, phosphins and } \\
\text { dynamin }\end{array}$ & 5 & 0.2 & $5.5 \mathrm{E}-2$ & $7.4 \mathrm{E}-1$ \\
\hline BioCarta & $\begin{array}{l}\text { Role of } \beta \text {-arrestins in the activation and } \\
\text { targeting of MAP kinases }\end{array}$ & 7 & 0.3 & $6.0 \mathrm{E}-2$ & 7.3E-1 \\
\hline BioCarta & $\begin{array}{l}\text { How progesterone initiates the oocyte } \\
\text { maturation }\end{array}$ & 8 & 0.4 & $8.5 \mathrm{E}-2$ & $8.2 \mathrm{E}-1$ \\
\hline BioCarta & Role of Ran in mitotic spindle regulation & 5 & 0.2 & $8.5 \mathrm{E}-2$ & $7.9 \mathrm{E}-1$ \\
\hline BioCarta & $\begin{array}{l}\text { ChREBP regulation by carbohydrates and } \\
\text { cAMP }\end{array}$ & 5 & 0.2 & $8.5 \mathrm{E}-2$ & $7.9 \mathrm{E}-1$ \\
\hline BioCarta & CFTR and b2AR pathway & 5 & 0.2 & $8.5 \mathrm{E}-2$ & $7.9 \mathrm{E}-1$ \\
\hline BioCarta & $\begin{array}{l}\text { Rho-selective guanine exchange factor } \\
\text { AKAP13 mediates stress fiber formation }\end{array}$ & 4 & 0.2 & $9.8 \mathrm{E}-2$ & $8.2 \mathrm{E}-1$ \\
\hline
\end{tabular}

${ }^{\mathrm{a}} \mathrm{Q}$, value calculated from p-value by Benjamini-Hochberg-Yekutieli multiple testing correction. ECM, extracellular matrix; PPAR, peroxisome proliferator-activated receptors; ERAD, endoplasmic-reticulum-associated degradation; AKAP, A-kinase anchoring protein; NDK, nucleoside diphosphate kinase; ChREBP, carbohydrate-responsive element-binding protein; CFTR, cystic fibrosis transmembrane conductance regulator; $\mathrm{b} 2 \mathrm{AR}, \beta 2$ adrenergic receptor

proteins bind to actin filaments and modulate their corresponding properties and functions. Myosin, an actin-dependent molecular motor, is involved in a number of important functions in spermiogenesis, such as acrosome biogenesis, vesicle transport, gene transcription and nuclear shaping $(38,39)$. In the current study, $\sim 94$ proteins were predicted to be involved in the regulation of the actin cytoskeleton in the round spermatids of mice (Fig. 8).
Numerous studies have focused on the proteomic analysis of spermatogenesis. Nevertheless, current knowledge on the proteome of round spermatids is limited, and the detailed protein patterns of round spermatids remain unknown. Thus, large-scale proteomic approaches such as the one employed in the present study, can provide a rich resource in the study of spermiogenesis, and enrich our knowledge on the biological functions of round spermatids. 
In conclusion, this study is the first, to the best of our knowledge, to conduct a proteomic analysis of round spermatids. Round spermatids are formed in a specific phase of spermatogenesis. We performed label-free quantification analysis and identified 2,287 unique proteins, which are involved in energy metabolism, transcription, protein synthesis and degradation, and nucleocytoplasmic transport. These biological processes facilitate the morphological changes to which round spermatids are subjected. The proteome analysis performed in the current study provided a comprehensive characterization of the protein expression profiles of round spermatids. Therefore, the present study is expected to enhance our understanding of the molecular basis of spermatogenesis.

\section{Acknowledgements}

This study was supported by the Scientific Research Foundation for Returned Scholars of Shanxi Province (2011-043, 2010-677).

\section{References}

1. Blanco-Rodriguez J and Martinez-Garcia C: Spontaneous germ cell death in the testis of the adult rat takes the form of apoptosis: re-evaluation of cell types that exhibit the ability to die during spermatogenesis. Cell Prolif 29: 13-31, 1996.

2. Jan SZ, Hamer G, Repping S, de Rooij DG, van Pelt AM and Vormer TL: Molecular control of rodent spermatogenesis. Biochim Biophys Acta 1822: 1838-1850, 2012.

3. Anway MD, Li Y, Ravindranath N, Dym M and Griswold MD Expression of testicular germ cell genes identified by differential display analysis. J Androl 24: 173-184, 2003.

4. O'Shaughnessy PJ, Fleming L, Baker PJ, Jackson G and Johnston H: Identification of developmentally regulated genes in the somatic cells of the mouse testis using serial analysis of gene expression. Biol Reprod 69: 797-808, 2003.

5. Schlecht U, Demougin P, Koch R, et al: Expression profiling of mammalian male meiosis and gametogenesis identifies novel candidate genes for roles in the regulation of fertility. Mol Biol Cell 15: 1031-1043, 2004.

6. Kovac JR, Pastuszak AW and Lamb DJ: The use of genomics, proteomics, and metabolomics in identifying biomarkers of male infertility. Fertil Steril 99: 998-1007, 2013.

7. Baker MA, Hetherington L, Reeves GM and Aitken RJ: The mouse sperm proteome characterized via IPG strip prefractionation and LC-MS/MS identification. Proteomics 8: 1720-1730, 2008.

8. Baker MA, Reeves G, Hetherington L and Aitken RJ: Analysis of proteomic changes associated with sperm capacitation through the combined use of IPG-strip pre-fractionation followed by RP chromatography LC-MS/MS analysis. Proteomics 10: 482-495, 2010.

9. Oliva R and Castillo J: Proteomics and the genetics of sperm chromatin condensation. Asian J Androl 13: 24-30, 2011.

10. Paz M, Morin M and Del Mazo J: Proteome profile changes during mouse testis development. Comp Biochem Physiol Part D Genomics Proteomics 1: 404-415, 2006.

11. Xun Z, Kaufman TC and Clemmer DE: Stable isotope labeling and label-free proteomics of Drosophila parkin null mutants. J Proteome Res 8: 4500-4510, 2009.

12. Cravatt BF, Simon GM and Yates JR III: The biological impact of mass-spectrometry-based proteomics. Nature 450: 991-1000, 2007.

13. Bauer KM, Lambert PA and Hummon AB: Comparative label-free LC-MS/MS analysis of colorectal adenocarcinoma and metastatic cells treated with 5-fluorouracil. Proteomics 12: 1928-1937, 2012.

14. Zhu W, Smith JW and Huang CM: Mass spectrometry-based label-free quantitative proteomics. J Biomed Biotechnol 2010: 840518, 2010.

15. Clough T, Thaminy S, Ragg S, Aebersold R and Vitek O: Statistical protein quantification and significance analysis in label-free LC-MS experiments with complex designs. BMC Bioinformatics 13: S6, 2012.
16. Merl J, Ueffing M, Hauck SM and von Toerne C: Direct comparison of MS-based label-free and SILAC quantitative proteome profiling strategies in primary retinal Muller cells. Proteomics 12: 1902-1911, 2012.

17. Niehl A, Zhang ZJ, Kuiper M, Peck SC and Heinlein M: Label-free quantitative proteomic analysis of systemic responses to local wounding and virus infection in Arabidopsis thaliana. J Proteome Res 12: 2491-2503, 2013.

18. Bellve AR, Cavicchia JC, Millette CF, O'Brien DA, Bhatnagar YM and Dym M: Spermatogenic cells of the prepuberal mouse. Isolation and morphological characterization. J Cell Biol 74: 68-85, 1977.

19. Keller A, Nesvizhskii AI, Kolker, E and Aebersold R: Empirical statistical model to estimate the accuracy of peptide identifications made by MS/MS and database search. Anal Chem 74: 5383-5392, 2002.

20. Nesvizhskii AI, Keller A, Kolker E and Aebersold R: A statistical model for identifying proteins by tandem mass spectrometry. Anal Chem 75: 4646-4658, 2003.

21. Wilkins MR, Sanchez JC, Gooley AA, et al: Progress with proteome projects: why all proteins expressed by a genome should be identified and how to do it. Biotechnol Genet Eng Rev 13: 19-50, 1996.

22. Wright PC, Noirel J, Ow SY and Fazeli A: A review of current proteomics technologies with a survey on their widespread use in reproductive biology investigations. Theriogenology 77: 738-765, 2012.

23. Macleod G and Varmuza S: The application of proteomic approaches to the study of mammalian spermatogenesis and sperm function. FEBS J 280: 5635-5651, 2013.

24. Gardiner-Garden M, Ballesteros M, Gordon M and Tam PP: Histone- and protamine-DNA association: conservation of different patterns within the beta-globin domain in human sperm. Mol Cell Biol 18: 3350-3356, 1998.

25. Miki K: Energy metabolism and sperm function. Soc Reprod Fertil Suppl 65: 309-325, 2007.

26. Bajpai M, Gupta G and Setty BS: Changes in carbohydrate metabolism of testicular germ cells during meiosis in the rat. Eur J Endocrinol 138: 322-327, 1998.

27. Nakamura M, Okinaga S and Arai K: Metabolism of round spermatids: kinetic properties of pyruvate kinase. Andrologia 19: 91-96, 1987.

28. Groettrup M, Pelzer C, Schmidtke G and Hofmann K: Activating the ubiquitin family: UBA6 challenges the field. Trends Biochem Sci 33: 230-237, 2008.

29. Pelzer C and Groettrup M: FAT10: Activated by UBA6 and functioning in protein degradation. Subcell Biochem 54: 238-246, 2010.

30. Jin J, Li X, Gygi SP and Harper JW: Dual E1 activation systems for ubiquitin differentially regulate E2 enzyme charging. Nature 447: 1135-1138, 2007.

31. Kopanja D, Roy N, Stoyanova T, et al: Cul4A is essential for spermatogenesis and male fertility. Dev Biol 352: 278-287, 2011.

32. Yi YJ, Manandhar G, Sutovsky M, et al: Ubiquitin C-terminal hydrolase-activity is involved in sperm acrosomal function and anti-polyspermy defense during porcine fertilization. Biol Reprod 77: 780-793, 2007.

33. Mtango NR, Sutovsky M, Susor A, Zhong Z, Latham KE and Sutovsky P: Essential role of maternal UCHL1 and UCHL3 in fertilization and preimplantation embryo development. J Cell Physiol 227: 1592-1603, 2012.

34. Tanaka $\mathrm{H}$ and Baba T: Gene expression in spermiogenesis. Cell Mol Life Sci 62: 344-354, 2005.

35. Ito C, Yamatoya K, Yoshida K, et al: Integration of the mouse sperm fertilization-related protein equatorin into the acrosome during spermatogenesis as revealed by super-resolution and immunoelectron microscopy. Cell Tissue Res 352: 739-750, 2013.

36. Dean KA, von Ahsen O, Gorlich D and Fried HM: Signal recognition particle protein 19 is imported into the nucleus by importin 8 (RanBP8) and transportin. J Cell Sci 114: 3479-3485, 2001.

37. van Nues RW, Leung E, McDonald JC, Dantuluru I and Brown JD: Roles for Srp72p in assembly, nuclear export and function of the signal recognition particle. RNA Biol 5: 73-83, 2008.

38. Sperry AO: The dynamic cytoskeleton of the developing male germ cell. Biol Cell 104: 297-305, 2012.

39. Sun X, Kovacs T, Hu YJ and Yang WX: The role of actin and myosin during spermatogenesis. Mol Biol Rep 38: 3993-4001, 2011. 